\title{
Observed coherent changes in climatic extremes during the second half of the twentieth century
}

\author{
P. Frich ${ }^{1, *}$, L. V. Alexander ${ }^{1, * *}$, P. Della-Marta ${ }^{2}$, B. Gleason ${ }^{3}$, M. Haylock ${ }^{2}$, \\ A. M. G. Klein Tank ${ }^{4}$, T. Peterson ${ }^{3}$ \\ ${ }^{1}$ Met Office, Hadley Centre for Climate Prediction and Research, London Road, Bracknell RG12 2SY, United Kingdom \\ ${ }^{2}$ Bureau of Meteorology (BoM), GPO Box 1289K, Melbourne, Victoria 3001, Australia \\ ${ }^{3}$ National Climatic Data Centre (NCDC), 151 Patton Avenue, Asheville, North Carolina 28801, USA \\ ${ }^{4}$ Royal Netherlands Meteorological Institute (KNMI), Postbus 201, 3730 AE De Bilt, The Netherlands
}

\begin{abstract}
A new global dataset of derived indicators has been compiled to clarify whether frequency and/or severity of climatic extremes changed during the second half of the 20th century. This period provides the best spatial coverage of homogenous daily series, which can be used for calculating the proportion of global land area exhibiting a significant change in extreme or severe weather. The authors chose 10 indicators of extreme climatic events, defined from a larger selection, that could be applied to a large variety of climates. It was assumed that data producers were more inclined to release derived data in the form of annual indicator time series than releasing their original daily observations. The indicators are based on daily maximum and minimum temperature series, as well as daily totals of precipitation, and represent changes in all seasons of the year. Only time series which had $40 \mathrm{yr}$ or more of almost complete records were used. A total of about 3000 indicator time series were extracted from national climate archives and collated into the unique dataset described here. Global maps showing significant changes from one multi-decadal period to another during the interval from 1946 to 1999 were produced. Coherent spatial patterns of statistically significant changes emerge, particularly an increase in warm summer nights, a decrease in the number of frost days and a decrease in intra-annual extreme temperature range. All but one of the temperaturebased indicators show a significant change. Indicators based on daily precipitation data show more mixed patterns of change but significant increases have been seen in the extreme amount derived from wet spells and number of heavy rainfall events. We can conclude that a significant proportion of the global land area was increasingly affected by a significant change in climatic extremes during the second half of the 20th century. These clear signs of change are very robust; however, large areas are still not represented, especially Africa and South America.
\end{abstract}

KEY WORDS: Observed climatic extremes · Derived indicators · Temperature · Precipitation · Climate monitoring $\cdot$ Global change

Resale or republication not permitted without written consent of the publisher

\section{INTRODUCTION}

Global change indicators are developed and maintained by many centres throughout the world. The aim of these aggregated indicators is to monitor climate

\footnotetext{
${ }^{*}$ Present address: National Environmental Research Institute (NERI), Postboks 358, Frederiksborgvej 399, 4000 Roskilde, Denmark

${ }^{* *}$ Corresponding author. E-mail: lisa.alexander@metoffice.com
}

change as and when it happens. The Intergovernmental Panel on Climate Change (IPCC 1995) concluded that anthropogenic effects have discernibly influenced the global climate, one effect being the rise in global mean temperature of $0.7^{\circ} \mathrm{C}$ since the second half of the 19th century (Nicholls et al. 1996, Parker et al. 2000). A rise in the mean would not necessarily lead to a rise in extreme temperature events. If the change in mean, however, was related to a shift in distribution then this could have a major impact on society and ecosystems, 
e.g. fewer frost days and increased heatwave duration. The research agenda, whilst being concerned with detection and attribution studies, has now also moved onto monitoring climate change. Nicholls et al. (1996) emphasised that further work on analysing changes in climatic extremes was required. The availability of a global daily dataset was, and still is, less than adequate for this kind of analysis (Folland et al. 2000). Indicators of climatic extremes have been developed through a number of international workshops (Folland et al. 1999, Nicholls \& Murray 1999, Manton et al. 2001). Increasingly, climate change detection and attribution studies have focussed on changes in extreme events (e.g. Easterling et al. 2000), which require daily observations. Access to a globally complete and readily available full resolution daily dataset is restricted for a number of reasons. Consequently we have defined 10 climatic indicators, which can be calculated locally by data-producing centres. Time series of these indicators can subsequently be exchanged between and used by both modelling groups and climate monitoring centres. Global datasets of unambiguously defined indicators could also provide the baseline data and benchmarks for evaluating climate change scenarios in the future. Both traditional climate change indicators and these new extreme indicators have been developed in close collaboration between leading international centres and will be available in near real time as resources allow. These indicators may form the basis for a future web-based and more coherent global information system on climate change monitoring based on Global Climate Observing Systems (GCOS) data. A tentative name for such a system would be the GCOS Extremes Monitoring (GEM) Network.

The aim of this paper is to clarify whether the frequency and/or severity of extreme weather and climate events have changed in recent decades. The problem of separating changes due to sampling, station exposure and real changes in extremes remains a challenge for the scientific community (Nicholls \& Murray 1999, Mohr 2000). We have chosen to use a fixed network of high-quality stations to reduce the effect of varying sampling biases.

This paper will build on existing available evidence for changes in climatic extremes. Section 2 will describe the rationale for developing and selecting the 10 indicators used in this study and the quality and availability of data. Section 3 will describe methods used in aggregating data and the methods used for testing whether any one time series displays a significant change over the analysis period. Global maps, time series and summary diagrams will be presented in Section 4, followed by our interpretation and discussion of the results in Section 5. Finally, we summarise our conclusions in Section 6.

\section{RATIONALE FOR ANALYSING INDICATORS OF CHANGING EXTREMES}

\subsection{Planning meetings}

Following a meeting of the World Meteorological Organisation (WMO) Commission for Climatology (CCl)/Climate Variability (CLIVAR) Working Group on Climate Change Detection in September 1998 (Folland et al. 1999), a number of meetings were held in Europe (European Climate Assessment [ECA] in Vienna, IPCC in Paris, Commission for Basic Systems Advisory Working Group [CBS AWG] in Reading, and WMO CCL/CLIVAR in Geneva), Australia (AustraliaPacific Network [APN] in Melbourne), and USA (IPCC in Asheville). It was realised at these meetings that insufficient time was available to collate a global daily dataset, analyse it and publish the results for inclusion in the IPCC Third Assessment Report. Subsequently, it was agreed that participants should exchange only derived indicator time series. This process has now resulted in the compilation of data files, each containing data derived from as many daily temperature and precipitation series as possible worldwide.

The WMO CCL/CLIVAR Joint Working Group on Climate Change Detection held another meeting in Geneva in November 1999, and recommended that a list of 10 simple and feasible indices be produced. This priority list of indices should be accompanied by methodologies and guidance on how to develop them for follow-up regional capacity building workshops in 2001.

It was also emphasised that development of indices should focus on indicators which were not highly correlated, but rather contain independent information. Indices should also be considered on a regional basis and compared within and between regions in addition to those for global analyses. Further consideration should also be given to developing indices to measure changes in climate variability on a variety of space and time scales.

A final requirement appeared from very recent studies of extremes (e.g. Manton et al. 2001, Zhang et al. 2001). Generally, these linear trend analyses of very rare events do not give significant results on traditional seasonal and regional scales. We realised that time series, which were based on just a few extreme events per year or season, would rarely provide the robustness needed. We thus had to limit our search for indicators accordingly. Robustness turned out to be a key requirement, and in the next section we will describe our selection of less extreme, and therefore less noisy, but hopefully more robust indicators. 
Table 1. Suggested 10 indicators for monitoring change in climatic extremes world-wide. Precise definitions of these and many other indicators are available at http://www.knmi.nl/samenw/eca/htmls/index2.html

\begin{tabular}{|c|c|c|c|}
\hline \multicolumn{2}{|c|}{ Indicator } & \multirow{2}{*}{$\begin{array}{l}\text { Definition } \\
\text { Total number of frost days (days with absolute minimum temperature }<0^{\circ} \mathrm{C} \text { ) }\end{array}$} & \multirow{2}{*}{$\begin{array}{l}\text { Unit } \\
\text { days }\end{array}$} \\
\hline 125 & $\mathrm{Fd}$ & & \\
\hline 141 & ETR & $\begin{array}{l}\text { Intra-annual extreme temperature range: difference between the highest temperature } \\
\text { observation of any given calendar year }\left(T_{\mathrm{h}}\right) \text { and the lowest temperature reading of the same } \\
\text { calendar year }\left(T_{1}\right)\end{array}$ & $0.1 \mathrm{~K}$ \\
\hline 143 & GSL & Growing season length: period between when $T_{\text {day }}>5^{\circ} \mathrm{C}$ for $>5 \mathrm{~d}$ and $T_{\text {day }}<5^{\circ} \mathrm{C}$ for $>5 \mathrm{~d}$ & days \\
\hline 144 & HWDI & $\begin{array}{l}\text { Heat wave duration index: maximum period }>5 \text { consecutive days with } T_{\max }>5^{\circ} \mathrm{C} \text { above } \\
\text { the 1961-1990 daily } T_{\max } \text { normal }\end{array}$ & days \\
\hline 194 & $\operatorname{Tn} 90$ & Percent of time $T_{\min }>90$ th percentile of daily minimum temperature & $\%$ \\
\hline 606 & R10 & No. of days with precipitation $\geq 10 \mathrm{~mm} \mathrm{~d}^{-1}$ & days \\
\hline 641 & CDD & Maximum number of consecutive dry days $\left(R_{\mathrm{day}}<1 \mathrm{~mm}\right)$ & days \\
\hline 644 & $\mathrm{R} 5 \mathrm{~d}$ & Maximum 5 d precipitation total & $0.1 \mathrm{~mm}$ \\
\hline 646 & SDII & Simple daily intensity index: annual total/number of $R_{\text {day }} \geq 1 \mathrm{~mm} \mathrm{~d}^{-1}$ & $0.1 \mathrm{~mm} \mathrm{~d}^{-1}$ \\
\hline 695 & R95T & Fraction of annual total precipitation due to events exceeding the 1961-1990 95th percentile & $\%$ \\
\hline
\end{tabular}

\subsection{Indicators selected}

The 10 selected indicators are listed in Table 1 with exact definitions available from the ECA website. The numbering system follows Frich et al. (1996) with later additions (Frich 1999) and some completely new indicators seen here for the first time (see Appendix 1).

These recommended indices potentially cover many aspects of a changing global climate. Frost days (Fd), measuring air frosts, would sample the winter halfyear in all extra-tropical regions, particularly the beginning and end of the cold season in many continental and high latitude climates. The intra-annual extreme temperature range (ETR) would span the most extreme high-temperature event of the summer season and the most extreme low-temperature event of the winter season. The heat wave duration index (HWDI) would sample the daytime maxima throughout the year in most climates and Tn90, which is the percent of observations exceeding the daily 90th percentile for the 1961-1990 base period, would sample primarily the warm nights during the year. Length of the thermal growing season (GSL) would sample spring and autumn anomalies in the higher latitudes.

The maximum number of consecutive dry days (CDD) could potentially become a valuable drought indicator for the dry part of the year, whilst the number of days with precipitation $\geq 10 \mathrm{~mm}$ (R10) and the simple daily intensity index (SDII) would similarly summarise the wet part of the year. The greatest $5 \mathrm{~d}$ precipitation total of the year (R5d) and the fraction of the annual total greater than or equal to the daily 95th percentile (R95T) would represent some of the more extreme precipitation events of the year.

\subsection{Data selected}

Trewin (1999) has developed a high-quality daily temperature dataset for Australia. These records have been adjusted for inhomogeneities at the daily timescale, by taking into account the magnitude of discontinuities for different parts of the distribution. Station records mostly extend from 1957, when digitised daily records are generally available in the Australian National Climate Centre's database, through to 1996. European temperature data have been collated as part of the European Climate Assessment (Klein Tank \& Wijngaard 2000). Time series have been carefully selected by national experts and have been scrutinised through visual inspection. Remaining temperature data have been provided from the National Climate Data Center (NCDC) archives (Peterson \& Vose 1997)

Precipitation stations from Australia were selected from the high-quality daily rainfall data set (Lavery et al. 1992). This data set was compiled from an exhaustive investigation of station history documentation to remove stations with bad exposure, instrumentation or observer accuracy. A series of statistical tests was utilised to further check the station integrity. Specific tests were also performed to check the influence of the change from imperial to metric units in 1974 as well as to check for bad observer practice. The 181 stations chosen provide a broad coverage of the country's main climatological regions.

European precipitation data have been collated as described above. Remaining national data throughout the world have been compiled by NCDC. These data were analysed for inhomogeneity with the most inhomogeneous time series discarded from the analysis 
(Peterson et al. 1998). The methodology used was that of the Global Climate Historical Network (GCHN; Peterson \& Vose 1997).

The criteria for including indicator time series based on daily data have varied from data source to data source. Generally, a year was considered missing in a station record if it contained $>10 \%$ missing daily values or $>3$ mo during the year contained $>20 \%$ missing daily values. Each station record used also needed to have at least 40 years worth of data between 1946 and 1999.

\section{METHODS}

Some extreme events are very localised (e.g. flooding in a narrow coastal zone or on one side of a mountain range), although they may still be part of a global pattern. Given the data sparsity and the lack of spatial coherency in some indicators, it was decided that the global maps should contain station data and not gridded data. In some parts of the world (e.g. South Africa, Europe and north-eastern USA) there were networks of higher density available. The large clusters of stations in

\section{No. of frost days with $\mathrm{Tmin}<0^{\circ} \mathrm{C}(125 \mathrm{Fd})$}

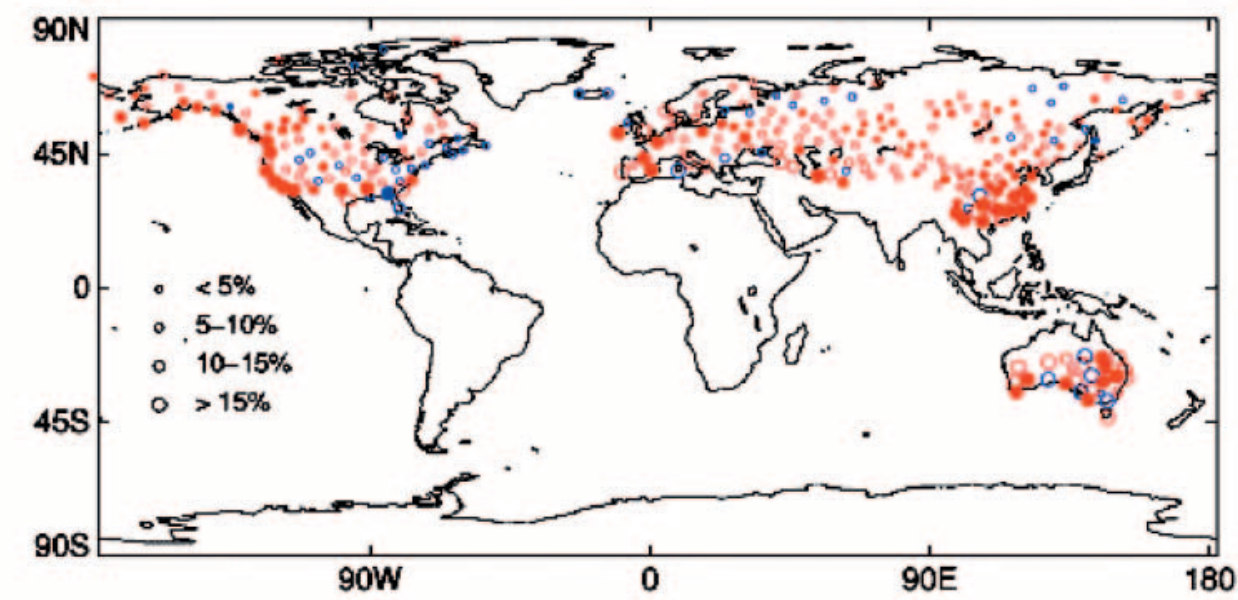

Blue is a positive change. Filled circles are significant at $95 \%$ level of confidence

Fd annual anomalies

b

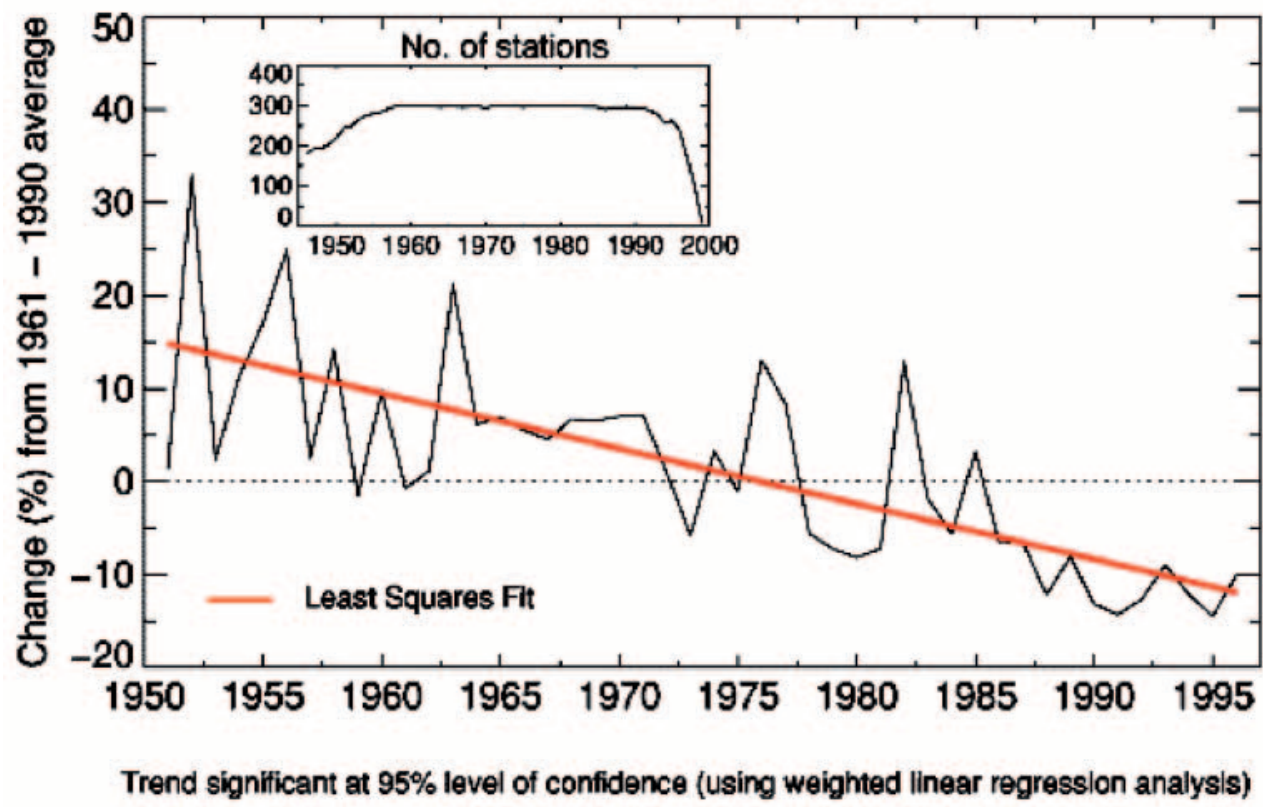

Fig. 1. Analysis of extreme indicator time series for number of frost days $(\mathrm{Fd}$; Table 1) during 2 multidecadal periods during the 2nd half of the 20th century. (a) Average number of Fd. Circle sizes represent the percentage change in the number of Fd (Table 1) at each station between the 2 multi-decadal periods. The colour coding specifies the sign of the change and the statistical significance of the change is calculated using a $t$-test (Appendix 2). (b) Differences in the average extreme indicator Fd value between 1951 and 1996 from the average 1961-1990 value of weighted global stations. The anomalies reflect the pattern of change in (a) through time. The insert represents the weighting factors used in the linear regression analysis, but note that the weights are shown for all years between 1946 and 1999 
these regions, particularly around coastal areas, would have had an undue influence on any global average calculation. For this study, as the correlation structure of the new indices is not yet known, we intentionally chose not to average any station data. Although future studies may justify some degree of averaging, we have chosen here to employ a network thinning technique to remove some of the bias towards the high-density station clusters. Assuming that the indicator time series were of equal quality, the network was thinned so that it was homogenised to a density of 1 to 2 stations $250000 \mathrm{~km}^{-2}$, as recom- mended by GCOS (http://www.wmo.ch/web/gcos) and others (Peterson et al. 1997). We then calculated a simple global average of all valid stations. The thinning technique is described in more detail in Appendix 2.

Two methods were employed to analyse each of the extreme indicator time series (see Appendix 2). The first method compares the average of one post-1946 multi-decadal period to another by means of a $t$-test. The length of the multi-decadal periods is determined by the length of each individual station record. The results are presented in Figs 1a to 10a and show both
Fig. 2. Analysis of extreme indicator time series for intra-annual extreme temperature range (ETR; Table 1). Significance of change, circle sizes, colour coding, differences in the average extreme indicator value, and insert as in Fig. 1

\section{Intra-annual Extreme Temperature Range (141 ETR)}

Change $(\%)$ between two multi-decadal averages during $2^{\text {nd }}$ half of $20^{\text {th }}$ Century

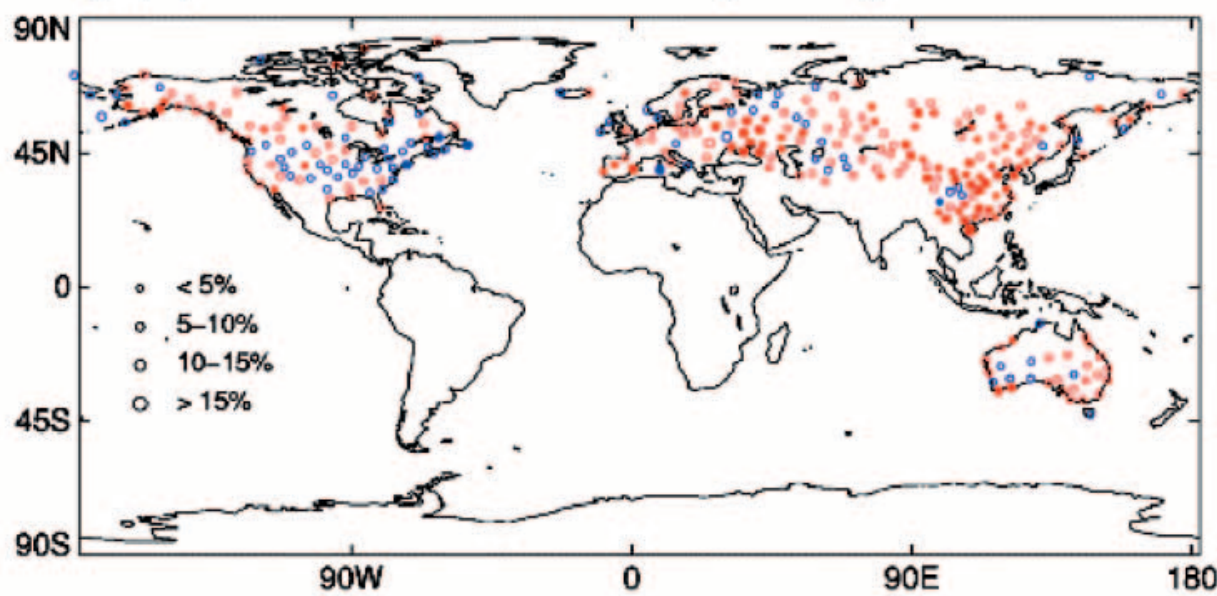

Blue is a positive change. Filled circles are significant at $95 \%$ level of confidence

\section{ETR annual anomalies}

b

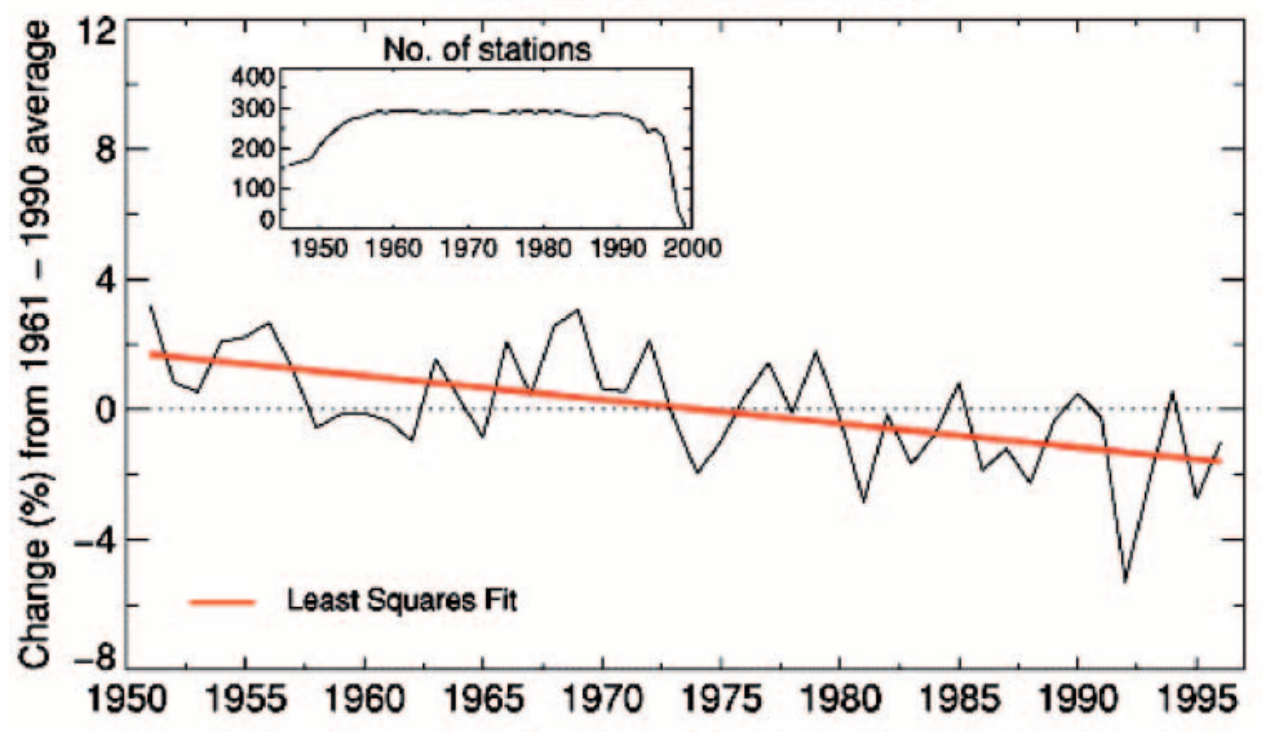

Trend significant at $95 \%$ level of confidence (using weighted linear regression analysis) 
the percentage change and significance of the change between these 2 periods for each station and extreme indicator. The second method aims to spatially average the results of each indicator time series. This was performed by calculating the anomalies in each year of the indicator time series from a base period of 1961-1990. The time series of this analysis can be seen in Figs $1 \mathrm{~b}$ to $10 \mathrm{~b}$. The trend of each has been calculated by weighting the anomalies according to the number of stations available from the network each year and has been tested for significance using weighted linear regression analysis (e.g. Draper \& Smith 1966).

Finally, probability density functions (PDFs) are calculated for each indicator. These are calculated by giving each indicator a number of 'bins' across its range and calculating the corresponding frequency, similar to producing histograms. The result is then normalised to sum to 1 to give estimated probabilities rather than a frequency distribution (Fig. 11).

\section{Thermal Growing Season Length (143 GSL)}

\section{Change (\%) between two multi-decadal averages during $2^{\text {nd }}$ half of $20^{\text {th }}$ Century}

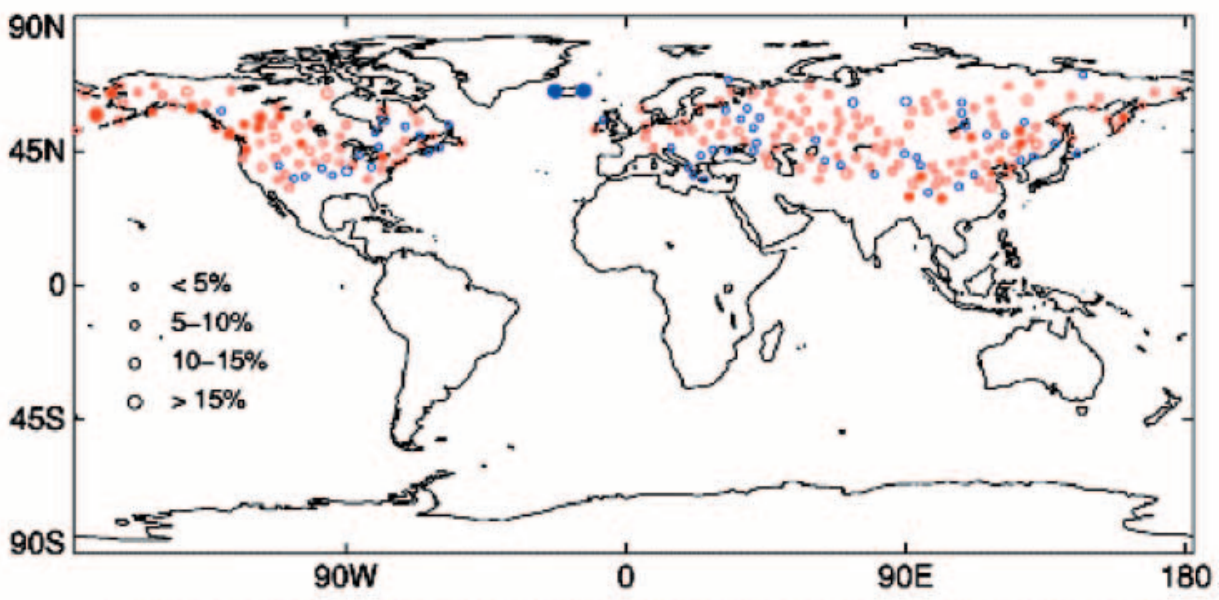

Red is a positive change. Filled circles are signilicant at $95 \%$ level of confidence

GSL annual anomalies

b

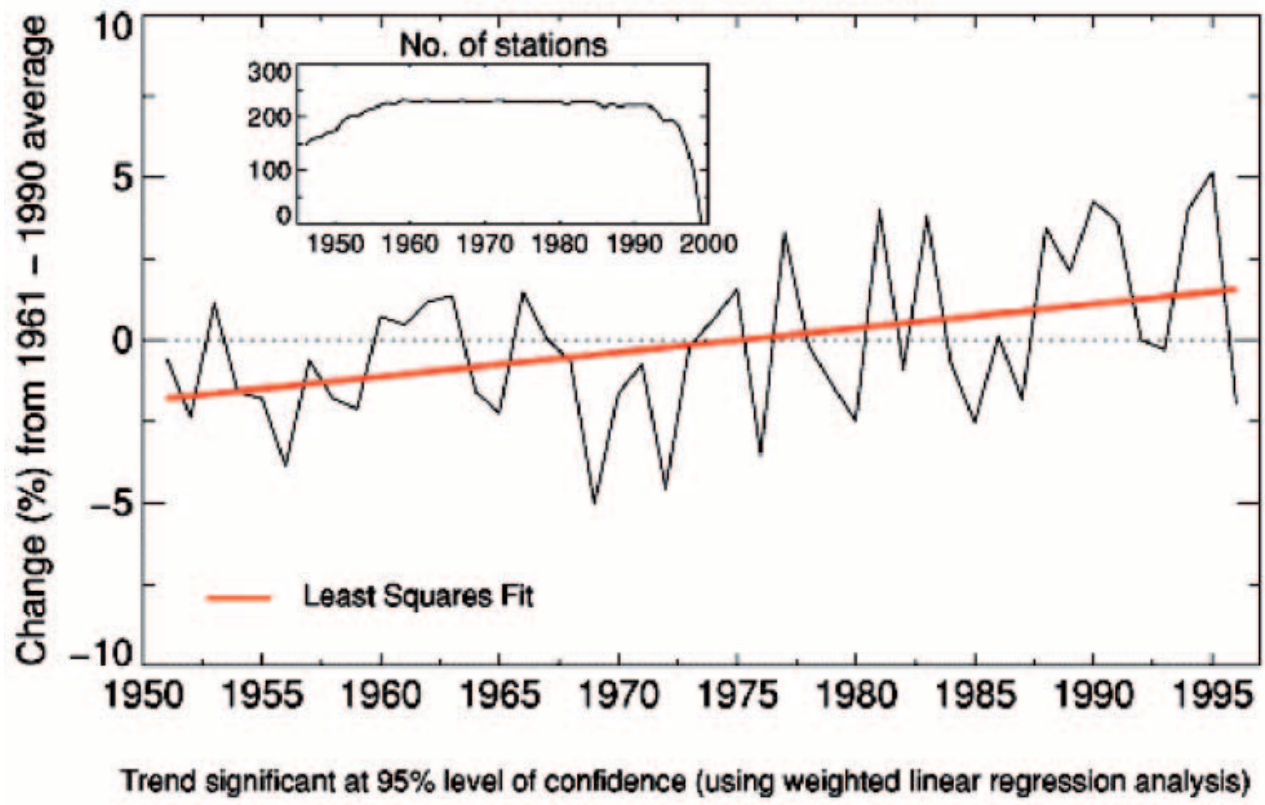

Fig. 3. Analysis of extreme indicator time series for growing season length (GSL; Table 1). Significance of change, circle sizes, colour coding, differences in the average extreme indicator value, and insert as in Fig. 1 


\section{RESULTS}

Each map (Figs 1a-10a) shows for all stations analysed whether or not there has been a statistically significant change from one multi-decadal average to the next during the second half of the 20th century. Note that colour coding changes between maps to associate wetter and cooler climate with blue and associate hotter and drier climate with red. For each indicator, we have also illustrated the development through time (see Figs $1 b-10 b)$ of the relative proportions of global sta- tions sampled affected by changes from the 1961-1990 base period. To help interpret these diagrams, we have provided an insert (Figs 1b-10b) showing the number of indicator time series used in the analysis along with Fig. 11 that shows the PDF for each indicator time series. The 2 PDFs shown in Fig. 11 for each extreme indicator correspond to the 2 multi-decadal periods used in the analysis shown in Figs 1a to 10a. The PDFs show the varied distribution of the climate indicators, some being severely skewed in both directions, while some are close to normal. We have not applied a stringent test for
Heat Wave Duration Index (144 HWDI) Change (\%) between two multi-decadal averages during $2^{\text {nd }}$ half of $20^{\text {th }}$ Century

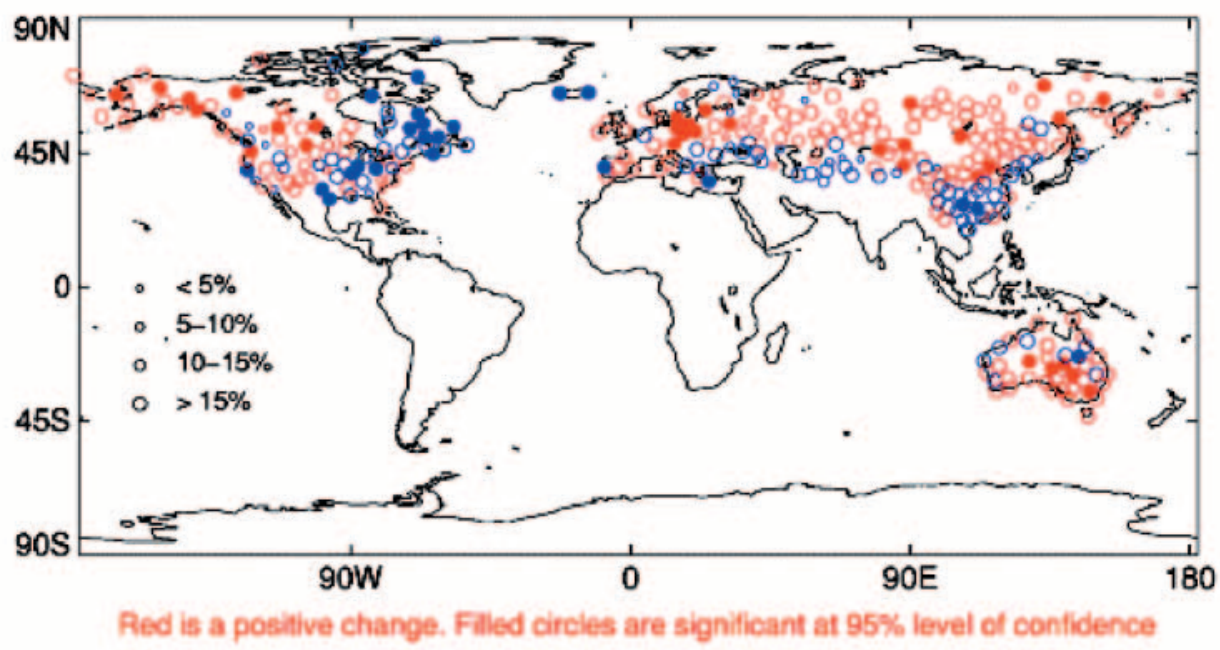

HWDI annual anomalies

b

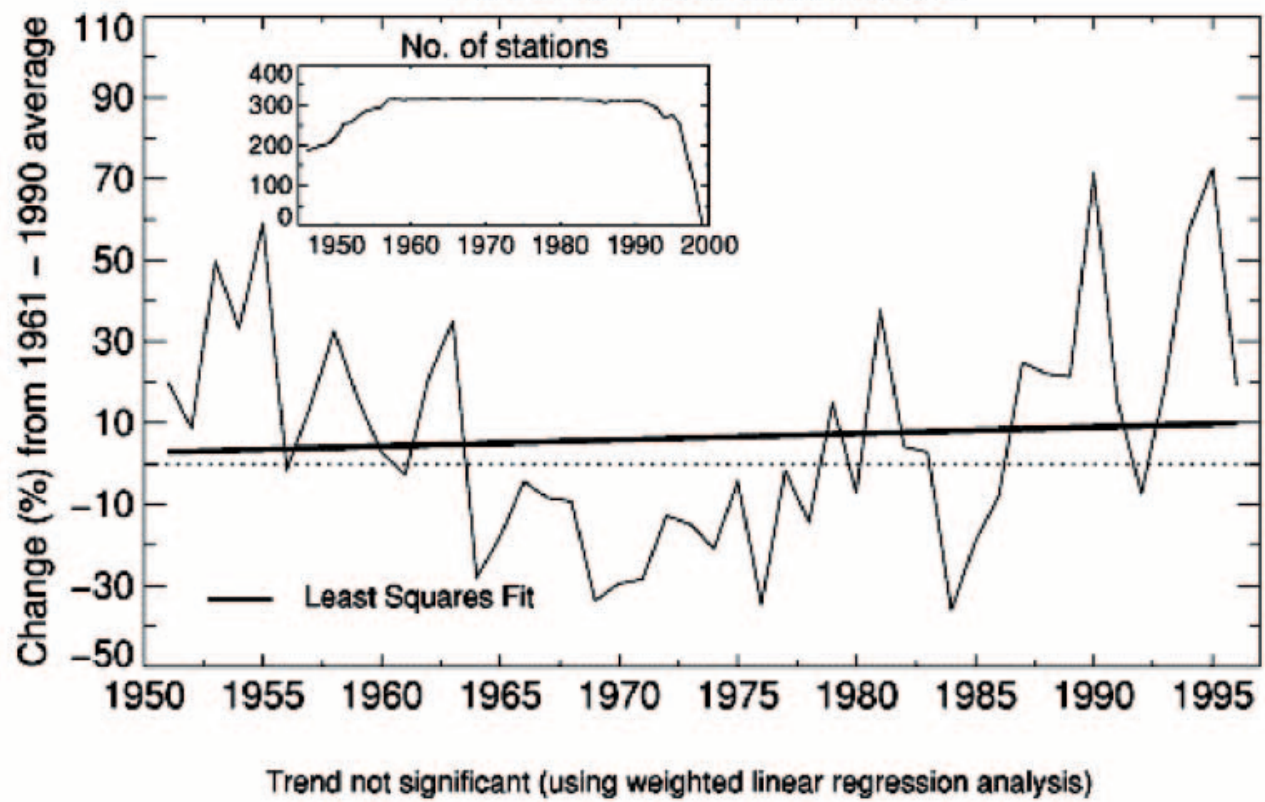

Fig. 4. Analysis of extreme indicator time series for heatwave duration index (HWDI; Table 1). Significance of change, circle sizes, colour coding, differences in the average extreme indicator value, and insert as in Fig. 1 
normality of distributions given that $t$-tests are robust against non-normal distributions (Ramsey \& Schafer 1997). However, in each case we recommend taking the shape of the PDF into account since the more normal-looking the distribution, the more confidence we can place in the result.

Finally, Fig. 12 summarises the observed changes over the period analysed. The data coverage is sparser at the beginning and end of this time frame, so we have only shown results between 1951 and 1996 .

\section{DISCUSSION}

\subsection{Temperature-based results}

Generally, the temperature-based indicator maps (Figs 1a-5a) seem to show roughly similar spatial patterns of change, although pattern correlations have not been performed. Most of the Northern Hemisphere and Australia show a warming over the 1946-1999 period. Notable exceptions are the south-central states

\section{Percent of time Tmin $>90^{\text {th }}$ percentile (194 Tn90) \\ a}

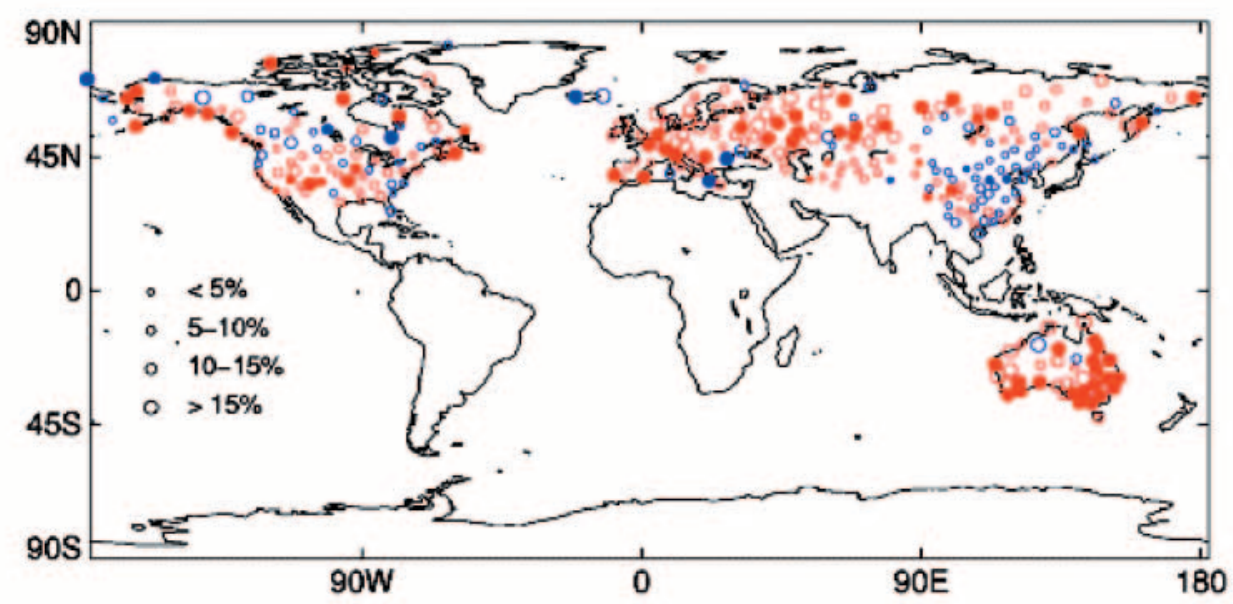

Red is a positive change. Filled circles are significant at $95 \%$ level of confidence

Tn90 annual anomalies

b

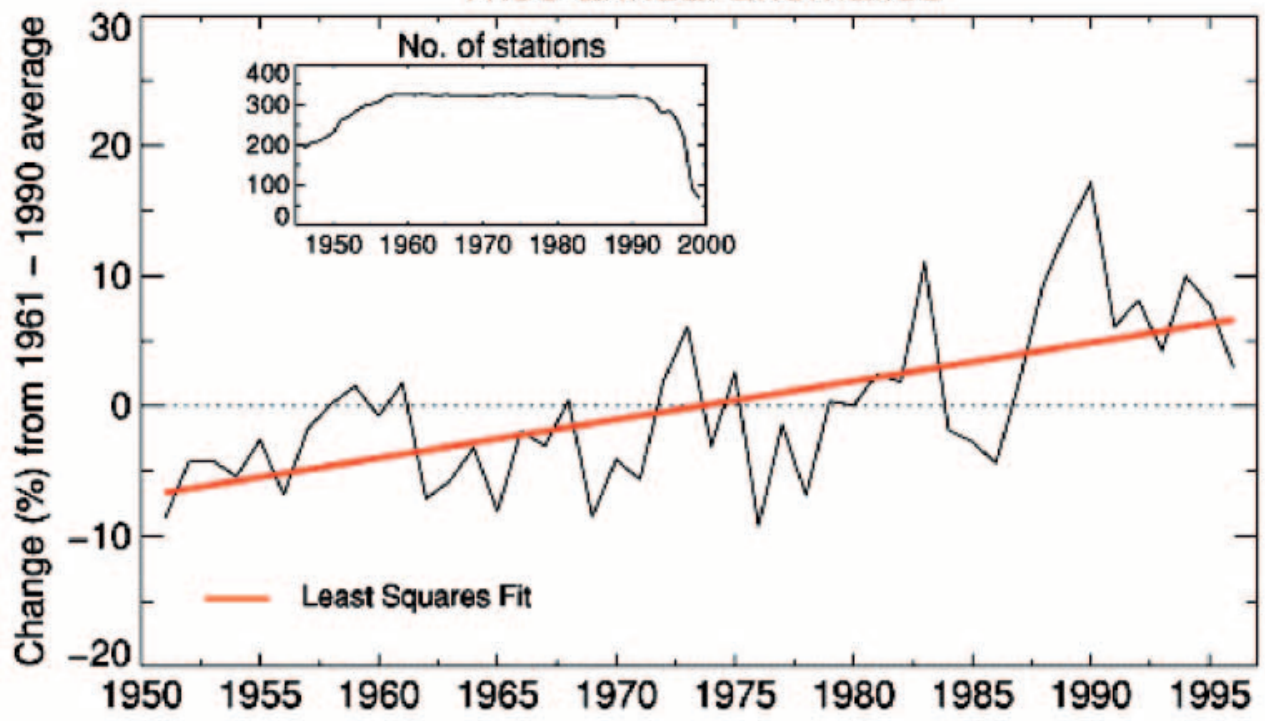

Trend significant at $95 \%$ level of confidence (using weighted linear regression analysis)

Fig. 5. Analysis of extreme indicator time series for percent of time when the daily minimum temperature is above the 90th percentile of the daily 1961-1990 value (Tn90; Table 1). Significance of change, circle sizes, colour coding, differences in the average extreme indicator value, and insert as in Fig. 1 
of the USA, eastern Canada and Iceland, as well as areas in central and eastern Asia. The temperaturebased indicator time series (Figs $1 \mathrm{~b}-5 \mathrm{~b}$ ) are intended to reflect the map-based results over time and show whether there is any significant change over the whole period analysed.

The annual number of frost days ( $F d)$ shows a near uniform global decrease over the second part of the 20th century (Fig. 1a). Most of the stations in the analysed areas show significantly fewer $\mathrm{Fd} \mathrm{yr}^{-1}$, when the most recent 20 to $27 \mathrm{yr}$ period is compared with a previous 20 to 27 yr period. Only a few stations in south-eastern USA and Iceland show a significant increase. Fig. 1b shows that there is a statistically significant decreasing trend in the number of stations experiencing frequencies of $\mathrm{Fd}$, which is in accord with the PDF for Fd in Fig. 11.

In many parts of the world, intra-annual extreme temperature range (ETR) shows a systematic and statistically significant decline over the past 4 to 5 de- a

Fig. 6. Analysis of extreme indicator time series for annual number of days with $\geq 10 \mathrm{~mm}$ of precipitation (R10 Table 1). Significance of change, circle sizes, colour coding, differences in the average extreme indicator value, and insert as in Fig. 1

b

\section{No. of days with precipitation $\geq 10 \mathrm{~mm}$ (606 R10) Change (\%) between two multi-decadal averages during $2^{\text {nd }}$ half of $20^{\text {th }}$ Century}

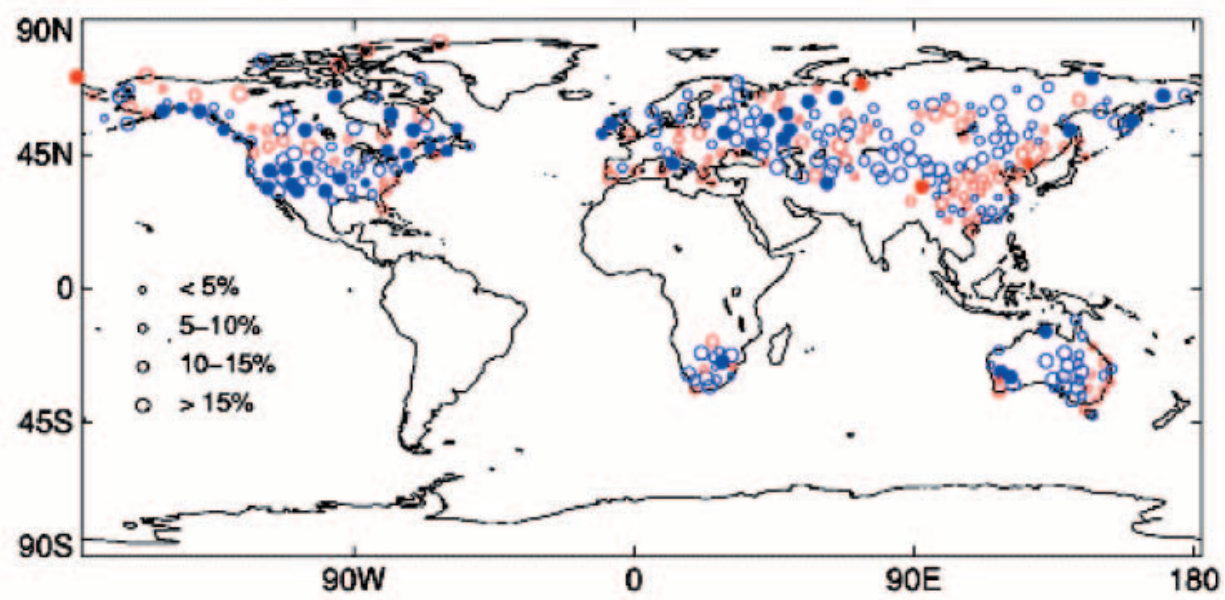

Blue is a positive change. Filled circles are significant at $95 \%$ level of confidence

\section{R10 annual anomalies}

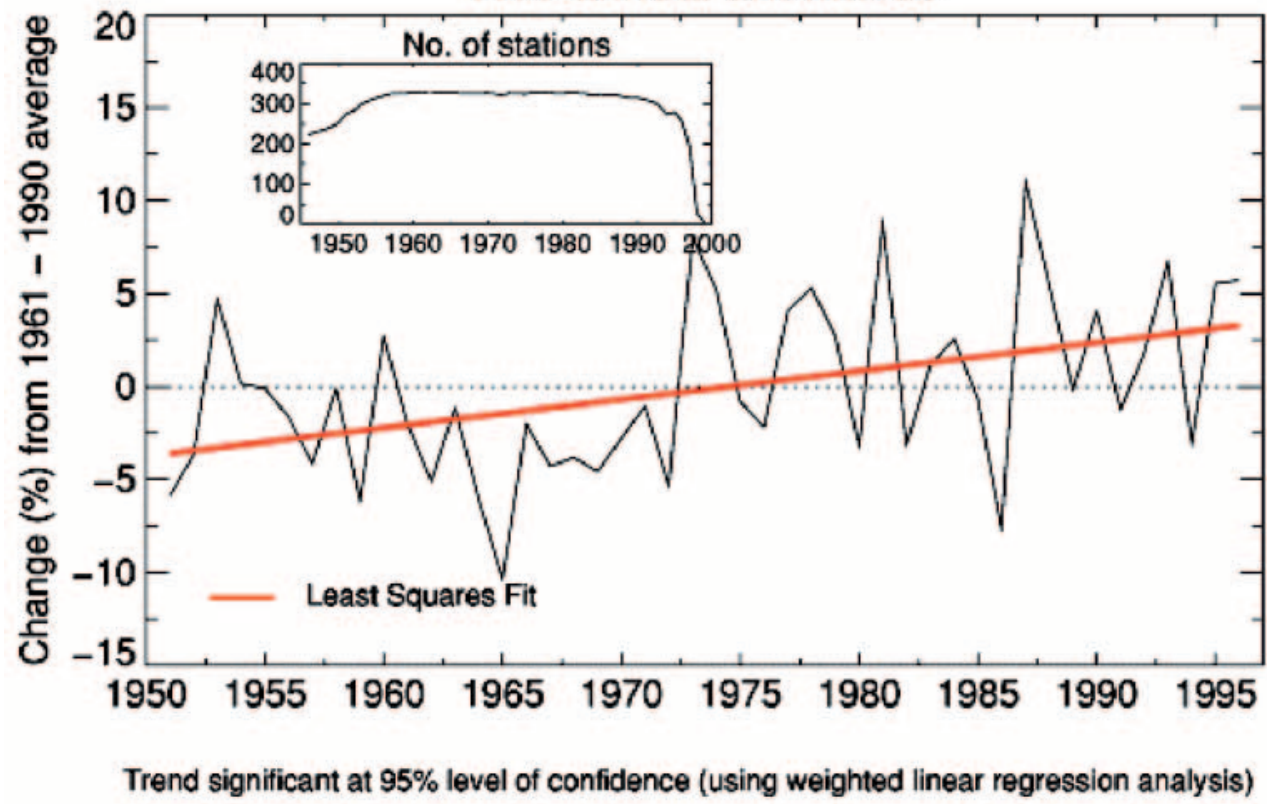


cades (Fig. 2a). Often the reductions from one multidecadal period to another are as large as several degrees and are mainly associated with increasing night-time temperatures (e.g. Tuomenvirta et al. 2000). Fig. $2 \mathrm{~b}$ shows that there was a significant decline in ETR over the period 1951-1996. Several previous studies (e.g. Plummer et al. 1995, Torok \& Nicholls 1996) have identified decreasing trends in diurnal temperature range throughout Australia over recent decades, largely due to minimum temperatures having increased more so than maximum temperatures. How- ever, ETR results do not stem from changes in cloud cover, as initial analyses have revealed that the 2 extreme ends of the temperature distribution often occur during clear sky conditions. The hottest temperature reading of the year is most often observed on a sunny afternoon, at least in the extra-tropics, whereas the coldest temperature reading of the year is most often observed on a clear winter night.

A lengthening of the thermal growing season (GSL) has been observed throughout major parts of the Northern Hemisphere mid-latitudes with the notable excep-

\section{Consecutive number of dry days (641 CDD)}

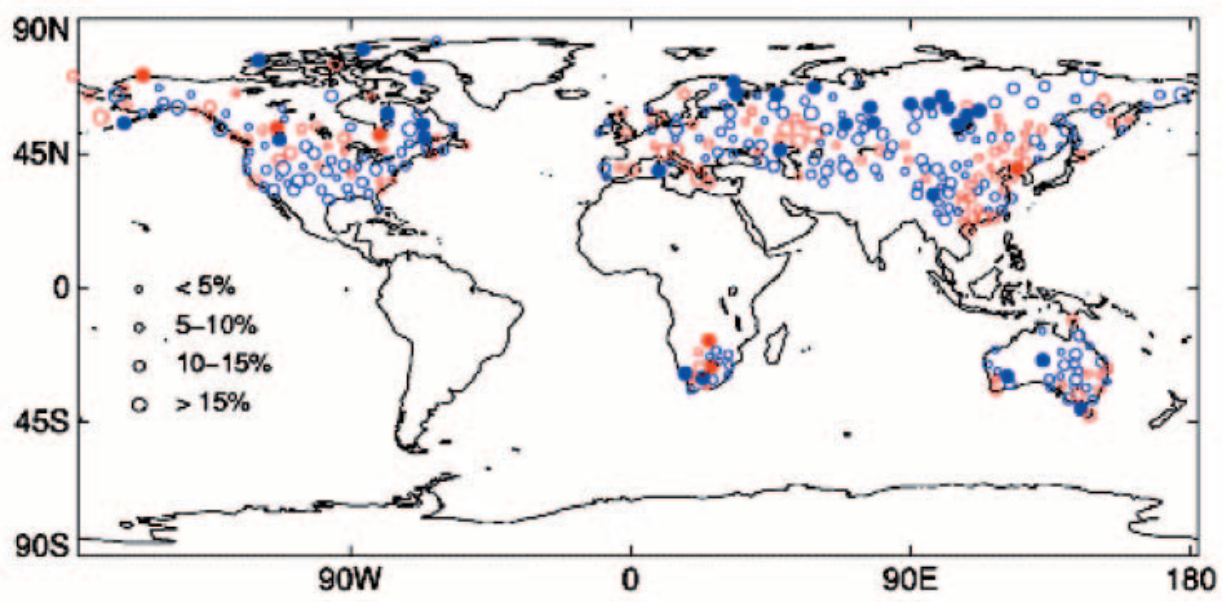

Red is a positive change. Filled circles are significant at $95 \%$ level of confidence

CDD annual anomalies

b

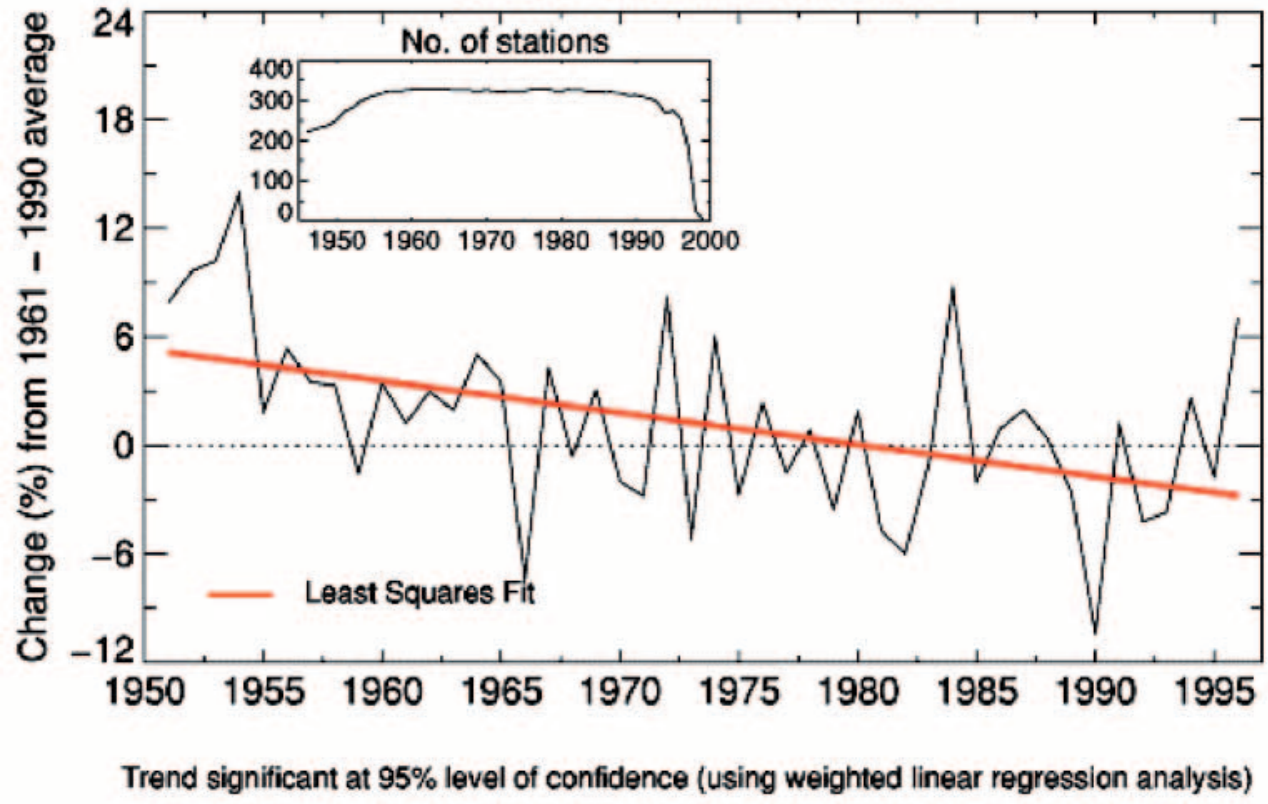

Fig. 7. Analysis of extreme indicator time series for consecutive number of days with $<1 \mathrm{~mm}$ precipitation (CDD; Table 1). Significance of change, circle sizes, colour coding, differences in the average extreme indicator value, and insert as in Fig. 1 
tion of Iceland (Fig. 3a). Growing season indices defined in global analyses are generally not appropriate for the relatively warm Australian climate. The majority of Australian stations would be considered to be in permanent growing conditions using many growing season definitions used elsewhere. In Australia, growing seasons tend to be crop specific and more dependent on rainfall patterns. Consequently there is no easily defined growing season index for this continent. Based only on the Northern Hemisphere stations there does appear to be a significant increase in GSL over time (Fig. 3b).
Significantly longer heat wave duration (HWDI) has been observed in Alaska, Canada, central and eastern Europe, Siberia and central Australia. Shorter heat waves have occurred in south-eastern USA, eastern Canada, Iceland and in southern China (Fig. 4a). The mixed results shown in Fig. 4a are supported by the fact that, although there appears to be a globally upward trend in HWDI (Fig. 4b), it is not statistically significant. HWDI has limited usefulness in warm climates with little day-to-day variability. For example, Kuwait, where temperatures may quite often reach a

Fig. 8. Analysis of extreme indicator time series for maximum $5 \mathrm{~d}$ precipitation total (R5d; Table 1). Significance of change, circle sizes, colour coding, differences in the average extreme indicator value, and insert as in Fig. 1

b

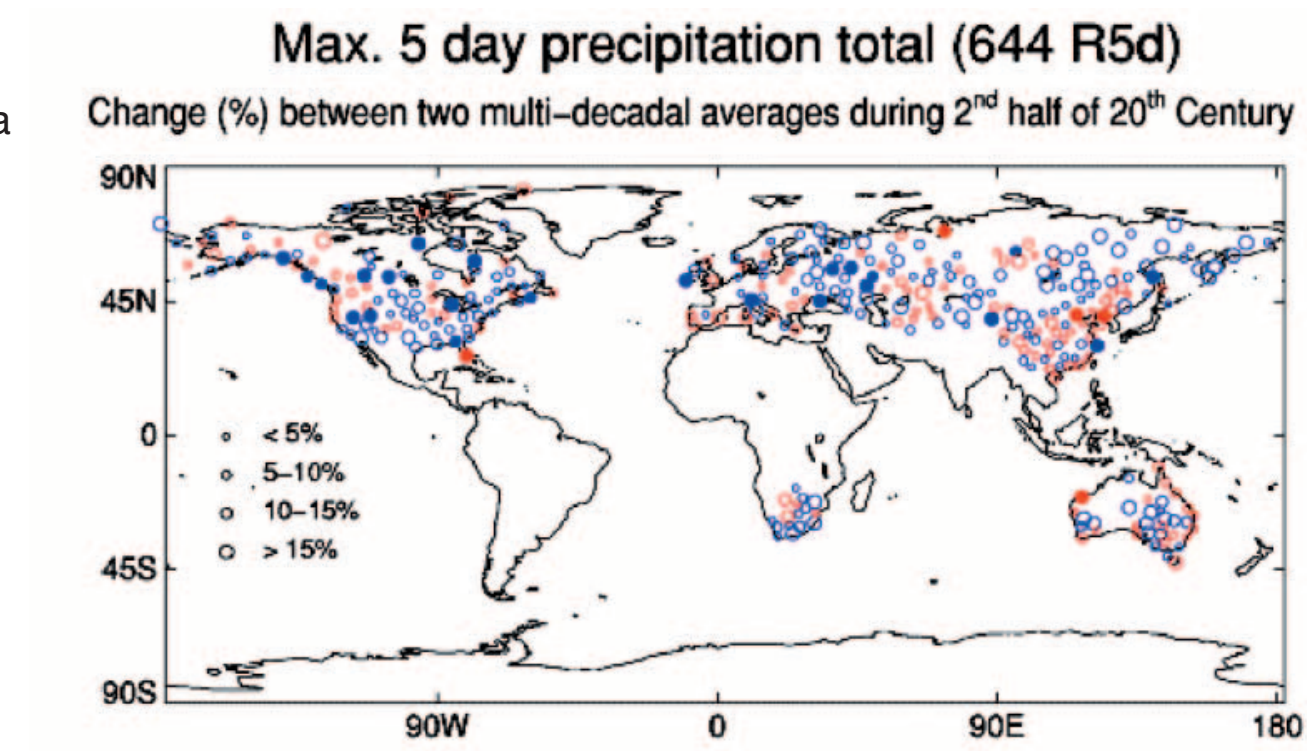

Blue is a positive change. Filled circles are significant at $95 \%$ level of confidence

\section{R5d annual anomalies}

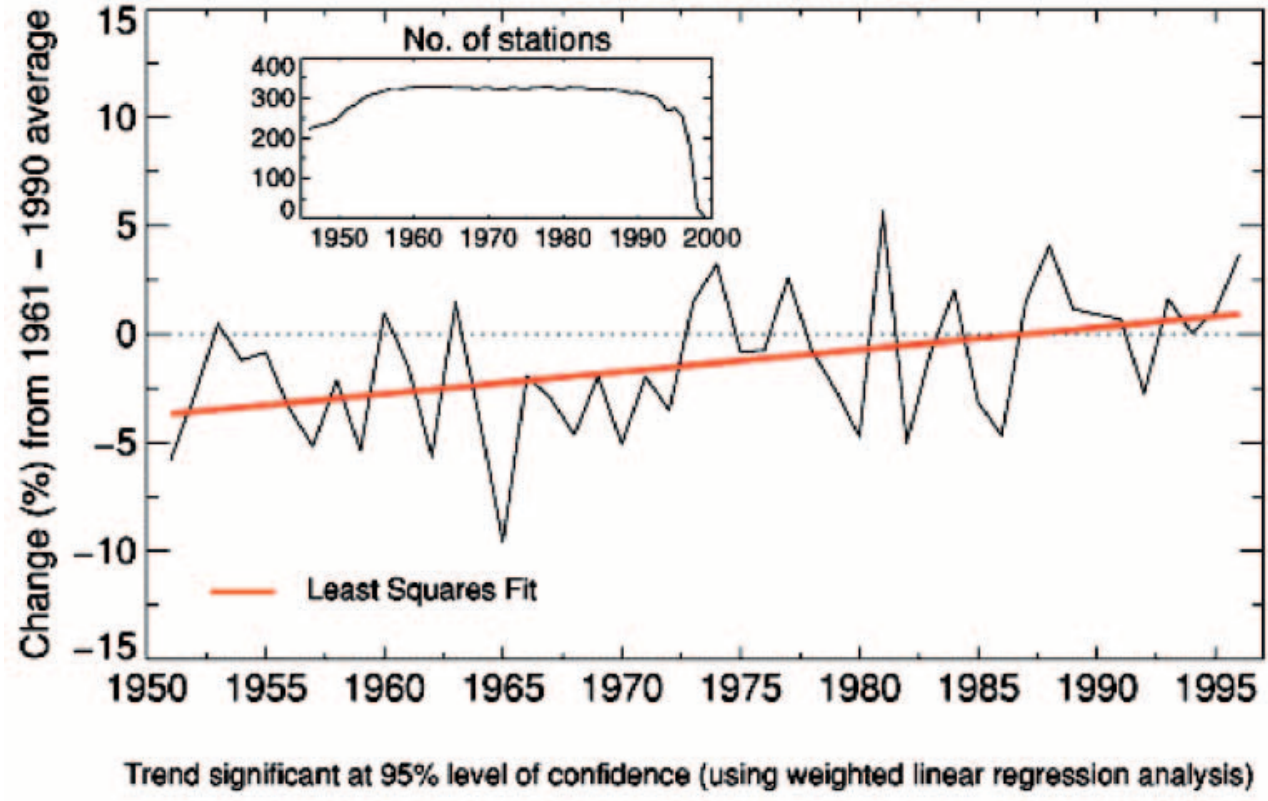


above $40^{\circ} \mathrm{C}$, the climate is so stable and the variability so subdued, that heat waves as defined in HWDI have never occurred.

The trend of warming nights is clear from the Tn90 indicator map (Fig. 5a), showing a general increase in most of the land areas examined with the exception of parts of Canada, Iceland, China and around the Black Sea. Generally, the frequency of warm minimum (Tn90) temperature extremes has increased throughout the world over the comparison periods to a significant extent. Fig. 5b again reflects this with the past decade showing an increase of about $15 \%$ from the 1961-1990 base period. This result should also be compared to its PDF from Fig. 11, which shows a slight shift in the distribution of Tn90 over the 2 periods sampled.

\subsection{Precipitation-based results}

Generally, all precipitation-based maps (Figs 6a10a) show a mixed pattern of positive and negative

\section{Simple Daily Intensity Index (646 SDII)}

a Change (\%) between two multi-decadal averages during $2^{\text {nd }}$ half of $20^{\text {th }}$ Century

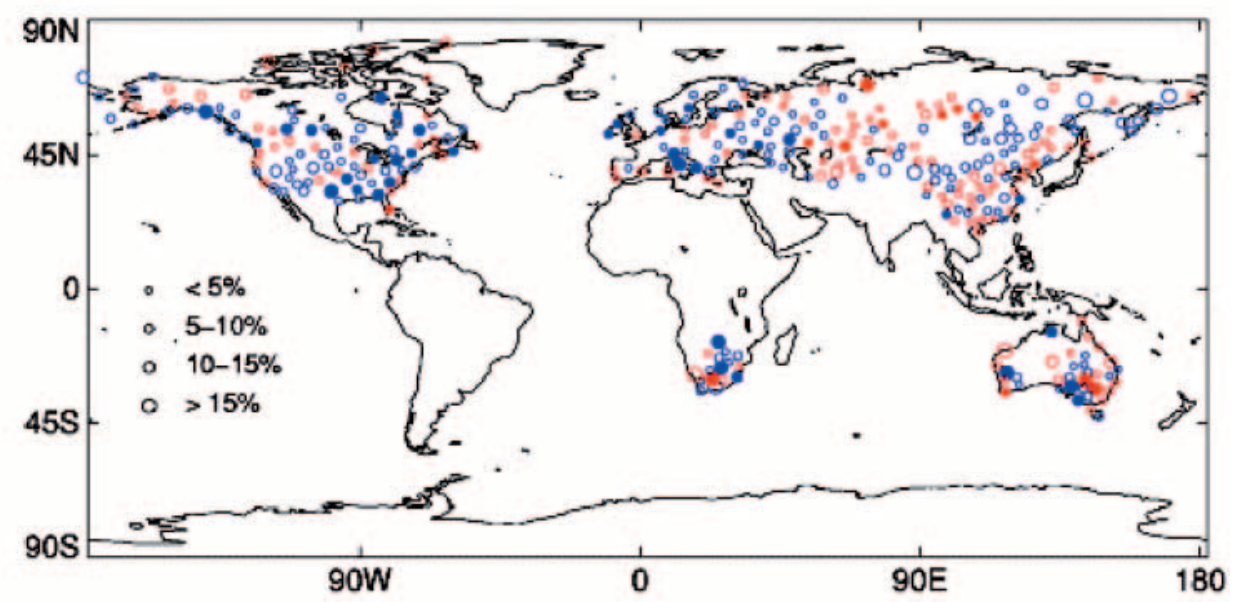

Blue is a positive change. Filled circles are significant at $95 \%$ level of confidence

\section{SDII annual anomalies}

b

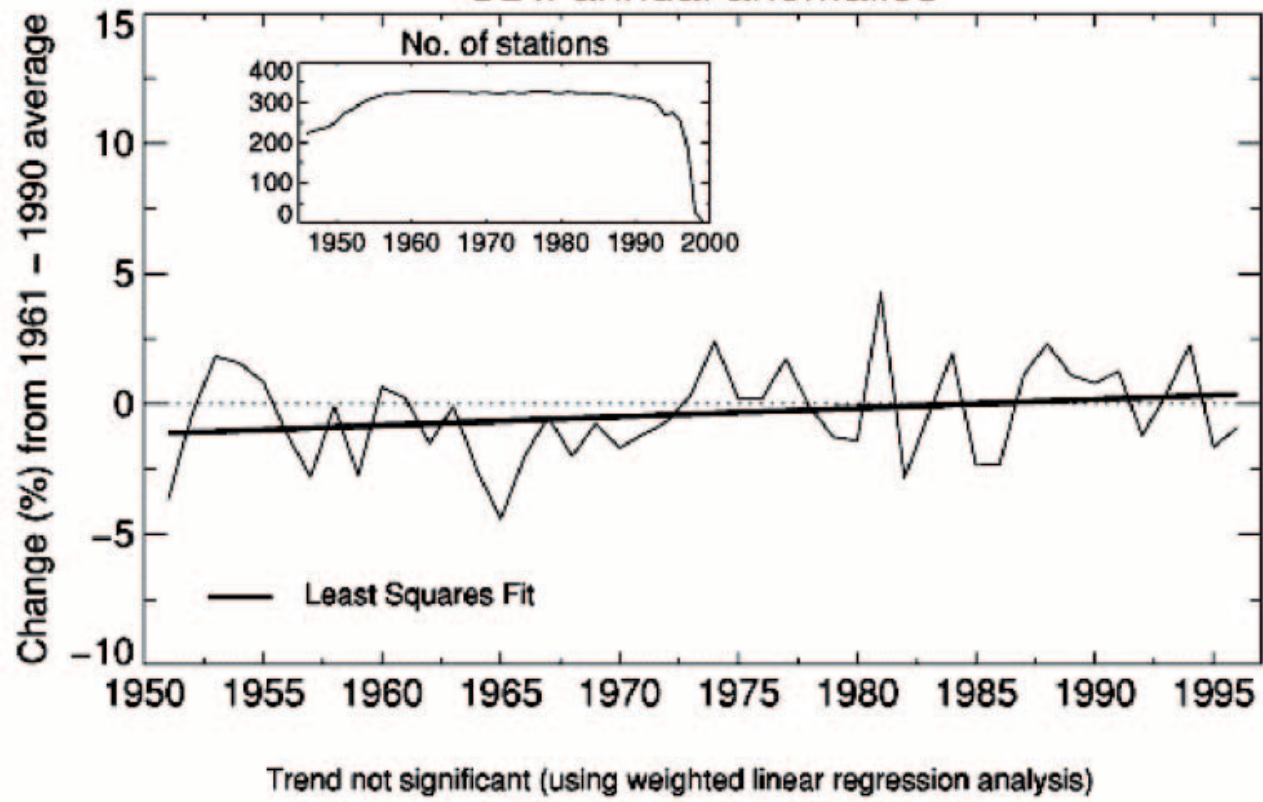

Fig. 9. Analysis of extreme indicator time series for simple daily intensity index (SDII; Table 1). Significance of change, circle sizes, colour coding, differences in the average extreme indicator value, and insert as in Fig. 1 
changes. Some of the more robust changes relating to wet extremes can be summarised as follows: southern Africa and south-east Australia, western Russia, parts of Europe and the eastern part of the USA all show a significant increase in most indicators of heavy precipitation events; eastern Asia and Siberia show a decrease in the frequency and/or the severity of heavy precipitation events. However, most of the precipitation indicators show a significant upward trend in their annual anomalies (Figs 6b-10b).
The number of days with precipitation $\geq 10 \mathrm{~mm}$ (R10) show that coherent patterns of a positive change (Fig. 6a) occur over Russia, USA and parts of Europe. The same applies for South Africa and most of Australia. Although the pattern is mixed, there is much more significant positive change than significant negative change. This can be compared to Fig. 6b, which shows this significant increasing trend. R10 is a simple index yet means very different things in different regions of the world. Some stations, e.g. on the Norwegian west coast, have, on average, $>120 \mathrm{~d}$ with precip-
Fig. 10. Analysis of extreme indicator time series for fraction of annual total precipitation due to events exceeding the 1961-1990 daily 95th percentile (R95T; Table 1). Significance of change, circle sizes, colour coding, differences in the average extreme indicator value, and insert as in Fig. 1

\section{Fraction of total precipitation $>95^{\text {th }}$ percentile (695 R95T) Change (\%) between two multi-decadal averages during $2^{\text {nd }}$ half of $20^{\text {th }}$ Century} a

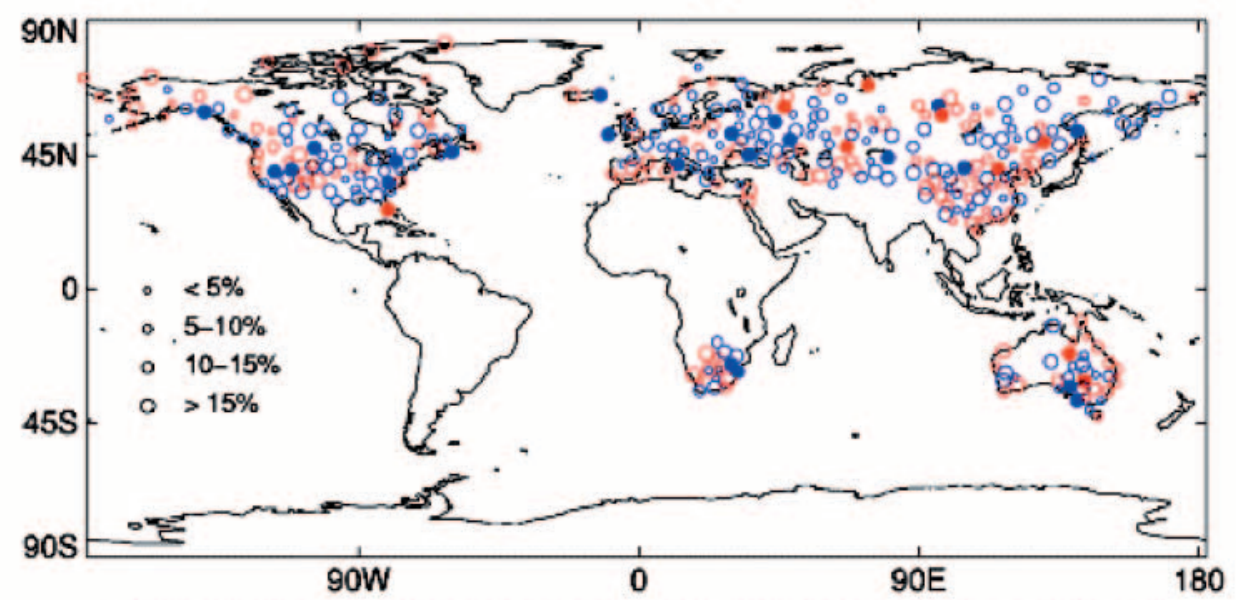

Blue is a positive change. Filled circles are significant at $95 \%$ level of confidence

R95T annual anomalies

b

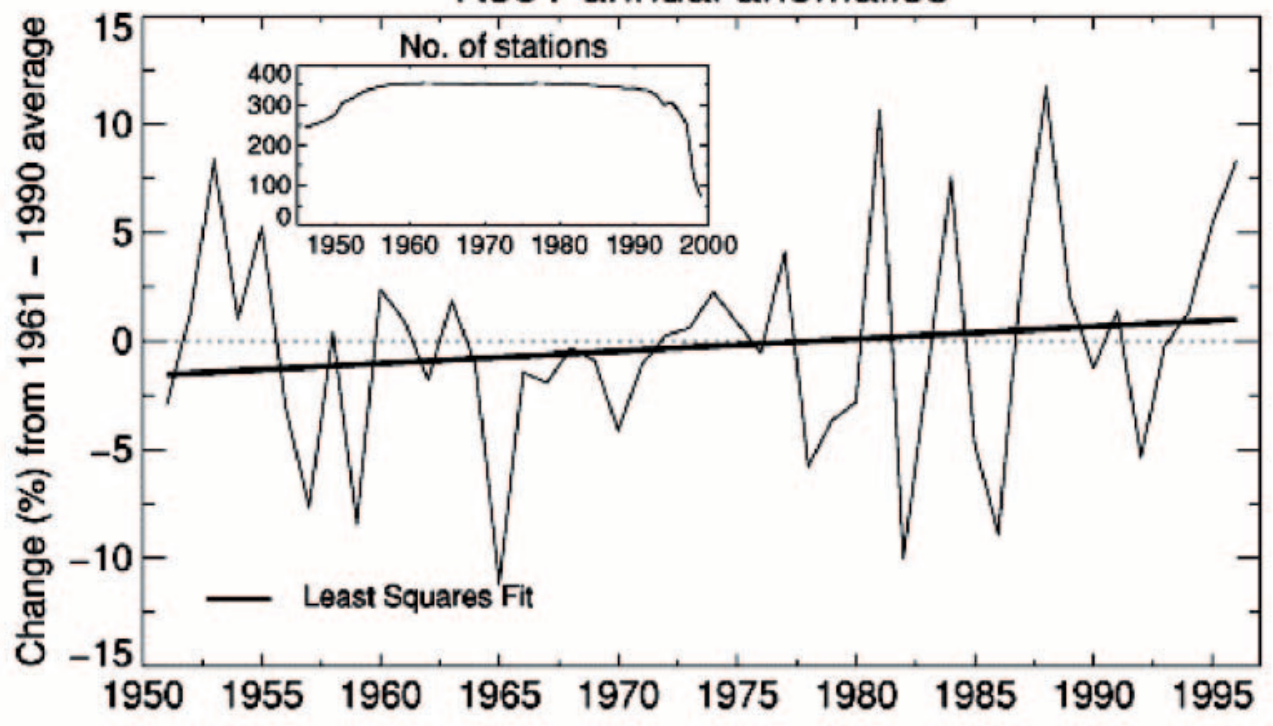

Trend not significant (using weighted linear regression analysis) 


\section{Change of Extreme Indicator Probability Density Functions}
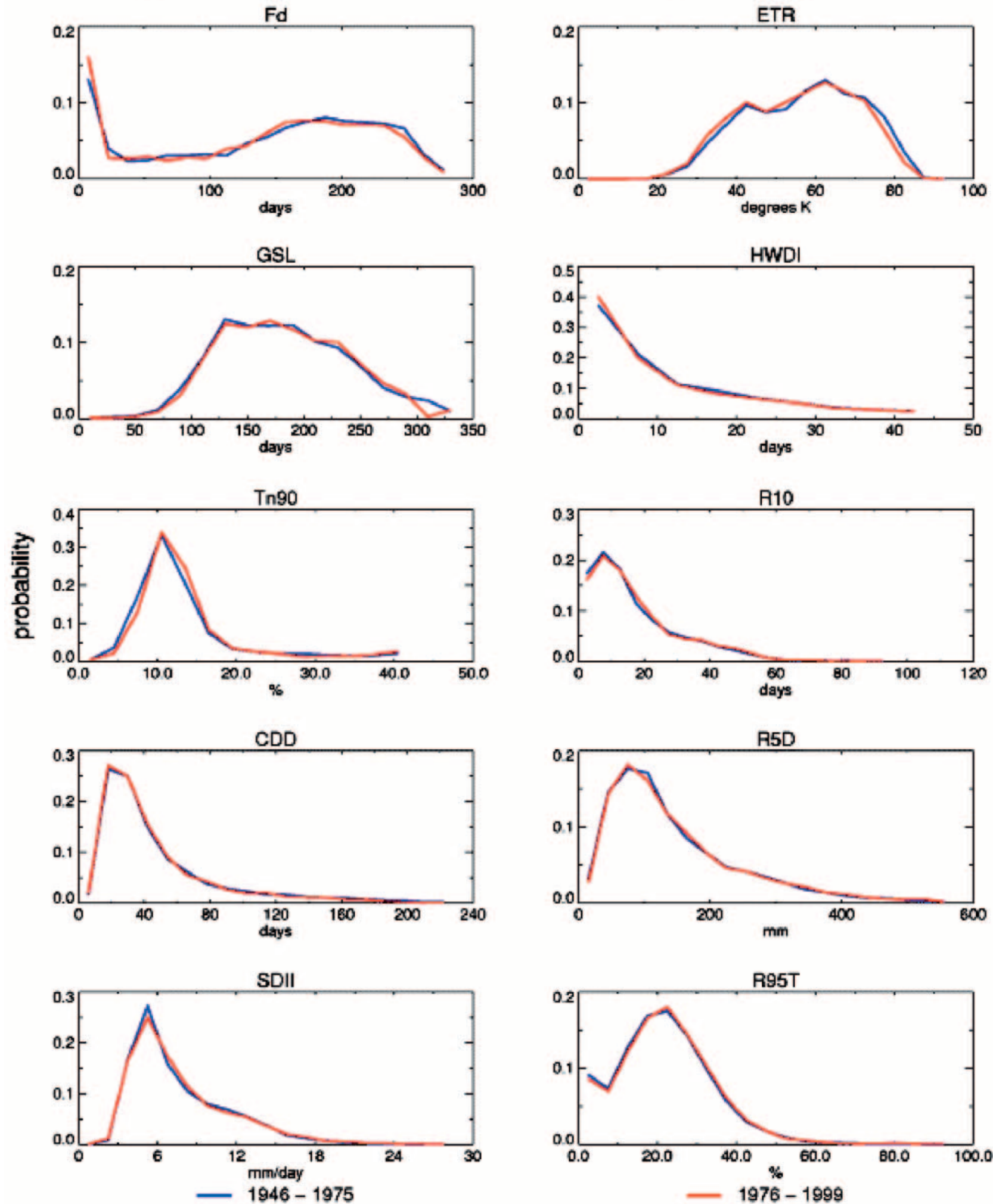

Fig. 11. Probability density functions showing change in distribution of the 10 extreme indicators (Table 1) over 2 multi-decadal periods in the second half of the 20th century 


\section{Significant changes in weighted global averages of extreme indicators Annual anomalies 1951-1996, relative to the 1961-1990 average}

Significant Positive Change
Precipitation

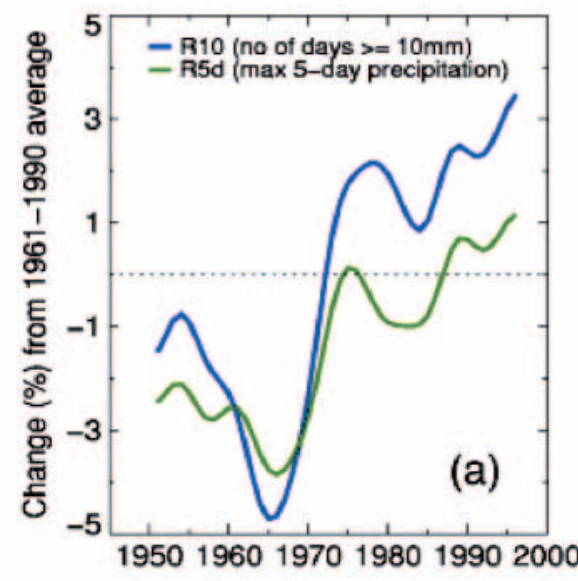

Significant Negative Change Precipitation

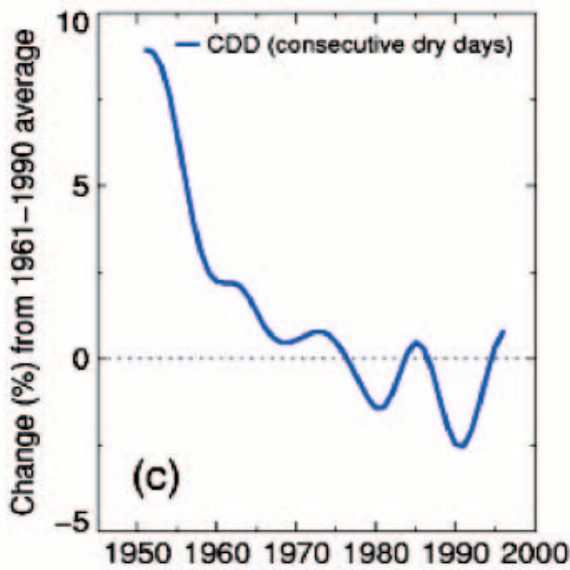

195019601970198019902000
Significant Positive Change Temperature

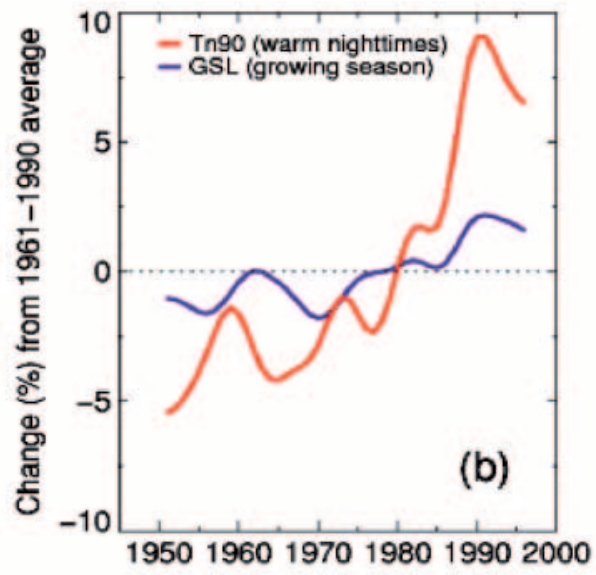

Significant Negative Change Temperature

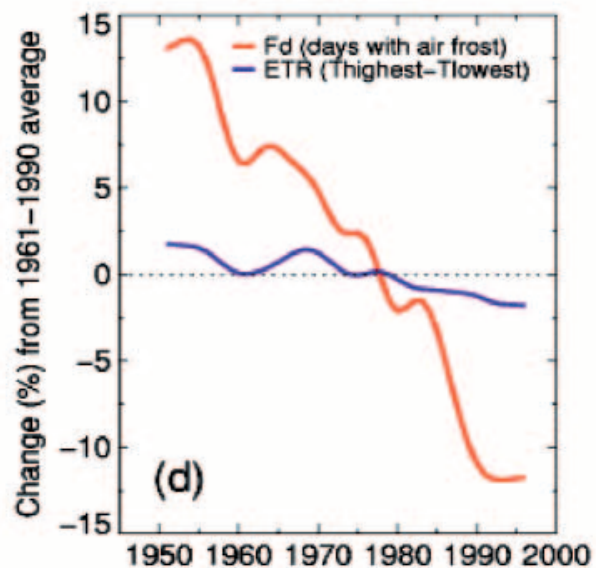

Fig. 12. Summary of the results from Figs $1 b-10 b$ which show a significant trend at the $95 \%$ level of confidence over the period from 1951-1996. Results have been smoothed using a 21-term binomial filter

itation $>10 \mathrm{~mm} \mathrm{yr}^{-1}$, while 1 of the inland stations in Australia has an average of only $4 \mathrm{~d} \mathrm{yr}^{-1}$. Nonetheless, $\mathrm{R} 10$ has proved to be a robust indicator, providing spatially homogeneous regions of both positive and negative changes.

The maximum number of consecutive dry days (CDD) shows in general a reduction (Fig. 7a) with notable exceptions in parts of South Africa, Canada and eastern Asia. This general pattern, however, is shown in the time series plot (Fig. 7b), which reflects the decreasing trend in CDD and its significance at the $95 \%$ level of confidence.

The maximum $5 \mathrm{~d}$ precipitation total (R5d) is the indicator of flood-producing events and shows a general increase throughout large areas of the globe.
Notable and coherent areas in western Russia and much of North America show a significant increase in this indicator. Some areas show a significant decline during the second half of the 20th century, e.g. eastern China. Again this pattern is reflected in the statistically significant upward trend of R5D (Fig. 8b).

The simple daily intensity index (SDII) is defined as the mean daily intensity for events $\geq 1 \mathrm{~mm} \mathrm{~d}^{-1}$. This has increased over many parts of Europe, southern Africa, USA and parts of Australia, although the patterns of change are also variable in these parts of the world showing some relatively nearby stations with opposite signs of change. The decrease in this index over eastern Australia reflects an increase in the number of rain days rather than a decrease in rainfall (Hennessy et al. 
1999). As the pattern is mixed, the trend is not significant although there does appear to be an increase in this indicator (Fig. 9b).

The fraction of annual total precipitation from events wetter than the 95th percentile of wet days ( $\geq 1 \mathrm{~mm}$ ) for 1961-1990 (R95T) shows that major increases have been observed in many parts of the USA, central Europe and southern Australia (Fig. 10a). There are a few coherent areas of decrease and hence we see an upward (but not significant) trend in Fig. 10b. The 1961-1990 95th percentile is the average of the 95th percentiles calculated for each year using all wet ( $\geq 1 \mathrm{~mm}$ ) days (or all wet days meeting the missing data criteria). The R95T index examines the contribution to total precipitation of a changing number of events. A year with more events above the threshold will almost always show a larger proportion of the total rainfall from these events simply because there are more events. At a later stage R95T may be redefined as the number of events above the threshold but for the purposes of this study we have chosen to include the totalling component.

\section{SUMMARY AND CONCLUSIONS}

\subsection{Circulation changes}

Dramatic regional and seasonal changes in UK precipitation have been linked to atmospheric circulation changes, specifically wetter winters (October to March) in north-west Scotland in recent decades (Osborn \& Jones 2000) and drier high summers (July and August) since the early 1970s in all regions of England and Wales (Alexander \& Jones 2001). These changes have very distinct impacts on the occurrence of extremes. It has been suggested that decreases in rainfall in south-west Australia, including extremes, have been caused by a southward shift in rain-producing weather patterns (Allan \& Haylock 1993). Whether these local or regional circulation changes are indeed local or part of a systematic global change, remains to be seen. The results presented here do indicate that a significant and growing proportion of the global land area analysed has been affected by changes in climatic extremes.

\subsection{Observed changes in extreme indicators}

We have observed a systematic increase in the 90th percentile of daily minimum temperatures (Tn90) throughout most of the analysed area, especially in the mid-latitudes and subtropics where data are available. This increase is accompanied by a similar reduction in the number of frost days (Fd) and a significant lengthening of the thermal growing season (GSL) in the extra-tropics in the Northern Hemisphere. The intraannual extreme temperature range (ETR) is based on only 2 observations $\mathrm{yr}^{-1}$; however, it provides a very robust and significant measure of declining extreme temperature variability. This particular indicator is considered a direct measure of anthropogenic impacts on the global atmosphere. Clear sky radiative heat loss during winter appears to have declined, as has the amount of incoming solar radiation during the summer. The latter may in part be explained by increasing amounts of jet contrails (Travis \& Changnon 1997, Minnis et al. 1999). The result is a clear global pattern of reduced intra-annual temperature variability and warrants future analysis of extreme cold and warm temperatures. There are still outstanding problems to resolve before a globally accepted definition of a heatwave duration indicator can be calculated and exchanged between National Meteorological Services (NMS) on a routine basis.

Our results show an increase in the frequency of heavy precipitation events (e.g. R10 and R5d) in some regions of the world, accompanied by changes in the drought frequency (CDD) in some regions of the world.

\subsection{Increasing global collaboration}

Global collaboration in developing, selecting and analysing 10 extreme indicators has led to a major achievement with respect to understanding patterns of changing extremes. This study builds on solid work in many NMS and is likely to initiate further regional efforts throughout the world.

Countries participating in the Asia-Pacific Network (APN) held successful meetings in December 1998 and December 1999. New datasets and analyses have become available and a major paper has been published (Manton et al. 2001).

The European Climate Assessment (ECA) held meetings in November 1998 and October 2000. Early results are available at: http://www.knmi.nl/samenw/ eca/index.html and a book will be published in 2001 . The European NMS will produce a CD-ROM of the daily dataset in 2001.

Collaboration between the University of the West Indies, NCDC and Caribbean countries resulted in a meeting in Jamaica in January 2001. The START Programme also supported a workshop in Casablanca in February 2001 to bring together NMSs in Africa. Future work will also include analysis of the GSN (Peterson et al. 1997). Extended east African collaboration has resulted in a much-improved database for countries from the Sudan to Mozambique. 
A coherent global climate information system will need to be based on a systematic naming convention for a limited number of well-defined climatic indicators. This will help to facilitate access to climate data and metadata as suggested by GCOS, and may help to secure a seamless interface within and between the main data providers. Increasingly, climate change monitoring will focus on changes in extreme events, which require an agreed set of indicators based on homogeneous series of daily observations. While this paper shows reliable results for the countries analysed, to gain a truly global understanding of changes in climatic extremes there is still much work needed to help other countries, e.g. Africa and South America, to homogenise their data.

Climate monitoring analyses need to be timely in order to enable us to give the best guidance to governments and other interested parties. We therefore need access to near real time observations with daily resolution, as well as a better global coverage. We need to create a climate information and data acquisition system which will serve a wide range of national and international requirements, such as those formulated by GCOS.

\subsection{Summary}

Examination of the results of this analysis indicates that, for the global land areas examined, on average during the second half of the 20th century, the world has become both warmer and wetter. Wet spells produce significantly higher rainfall totals now than they did just a few decades ago. Out of 10 indicators analysed on a global scale over the past 5 decades 7 give coherent and significant results. Heavy rainfall events have become more frequent and cold temperature extremes have become less frequent during the second half of the 20th century. These observed changes in climatic extremes are in keeping with expected changes under enhanced greenhouse conditions.

Acknowledgements. Dr Pasha Ya. Groisman provided a lot of Russian data. South African data from Johan Koch was kindly provided by the South African Weather Bureau.

\section{LITERATURE CITED}

Alexander LV, Jones PD (2001) Updated precipitation for the UK with discussion of extremes. Atmos Sci Lett (in press)

Allan RJ, Haylock MR (1993) Circulation features associated with the winter rainfall decrease in south-western Australia. J Clim 6:1356-1367

Draper NR, Smith H (1966) Applied regression analysis, John Wiley \& Sons, New York
Easterling DR, Meehl GA, Parmesan C, Chagnon SA, Karl T, Mearns LO (2000) Climate extremes: observation, modeling and impacts. Science 289:2068-2074

Folland CK, Horton EB, Scholefield P (eds) (1999) Report of WMO Working Group on Climate Change. Detection Task Group on Climate Change Indices, Bracknell, 1 September 1998, WMO TD 930

Folland CK, Frich P, Rayner N, Basnett T, Parker DE, Horton B (2000) Uncertainties in climate data sets - a challenge for WMO. WMO Bull 49(1):59-68

Frich P (1999) REWARD-A Nordic Collaborative Project Annex. In: Folland CK, Horton EB, Scholefield PR (eds) Meeting of the Joint CCl/CLIVAR Task Group on Climate Indices, Bracknell, UK, 2-4 September 1998. World Climate Data and Monitoring Programme, WCDMP-No. 37, WMO-TD No. 930

Frich P, Alexandersson H, Ashcroft J, Dahlström B and 14 others (1996) North Atlantic Climatological Dataset (NACD Version 1) Final Report. Danish Meteorological Institute, Scientific Report 96-1 (also available at: http://web.dmi. $\mathrm{dk} / \mathrm{f}+\mathrm{u} /$ publikation/videnskabrap.html)

Hennessy KJ, Suppiah R, Page CM (1999) Australian rainfall changes, 1910-1995. Aust Meteorol Mag 48:1-13

IPCC (1995) Climate change 1995: the science of climate change. Houghton JT, Meira Filho LG, Callender BA, Harris N, Kattenberg A, Maskell K (eds). Cambridge University Press, Cambridge, p 132-192, 289-357

IPCC (2001) Climate change 2001: the Scientific Basis Contribution of Working Group I to the Third Assessment Report of the Intergovernmental Panel on Climate Change. Houghton JT, Ding Y, Griggs DJ, Noguer M, van der Linden PJ, Dai X, Maskell K, Johnson CA (eds) Cambridge University Press, Cambridge (in press)

Klein Tank AMG, Wijngaard JB (2000) European climate assessment. In: Falchi MA, Zorini AO (eds) Proceedings of the 3rd European Conference on Applied Climatology, 16-20 October 2000, Pisa. IATA-CNR CD-ROM, Florence

Lavery B, Kariko A, Nicholls N (1992) A historical rainfall data set for Australia. Aust Meteorol Mag 40:33-39

Manton MJ, Della-Marta PM, Haylock MR, Hennessy KJ and 23 others (2001) Trends in extreme daily rainfall and temperature in southeast Asia and the South Pacific: 1961-1998. Int J Climatol 21:269-284

Minnis P, Schumann U, Doelling DR, Gierens KM, Fahey DW (1999) Global distribution of contrail radiative forcing. Geophys Res Lett 26(13):1853-1856

Mohr N (2000) Storm warning, global warming and the rising costs of extreme weather. Global Change (electronic edn). April 2000: http://www.globalchange.org/allissu2000b. htm\#2000apr-science

Nicholls N, Murray W (1999) Workshop on indices and indicators for climate extremes: Ashville, NC, USA, 3-6 June 1997-Breakout Group B: Precipitation. Clim Change 42: 23-29

Nicholls N, Gruza GV, Jouzel J, Karl TR, Ogallo LA, Parker DE (1996) Chap 3. Observed climate variability and change. In: Houghton JT, Meira Filho LG, Callander BA, Harris N, Kattenberg A, Maskell K (eds) Climate change 1995: the science of climate change. Contribution of Working Group I to the Second Assessment Report of the Intergovernmental Panel on Climate Change. Cambridge University Press, Cambridge, p 137-192

Osborn T, Jones PD (2000) Air flow influences on local climate: observed United Kingdom climate variations. Atmos Sci Lett 1:(in press)

Parker DE, Horton EB, Alexander LV (2000) Global and regional climate in 1999. Weather 55:188-199 
Appendix 1. Indicators for monitoring change in climatic extremes world-wide

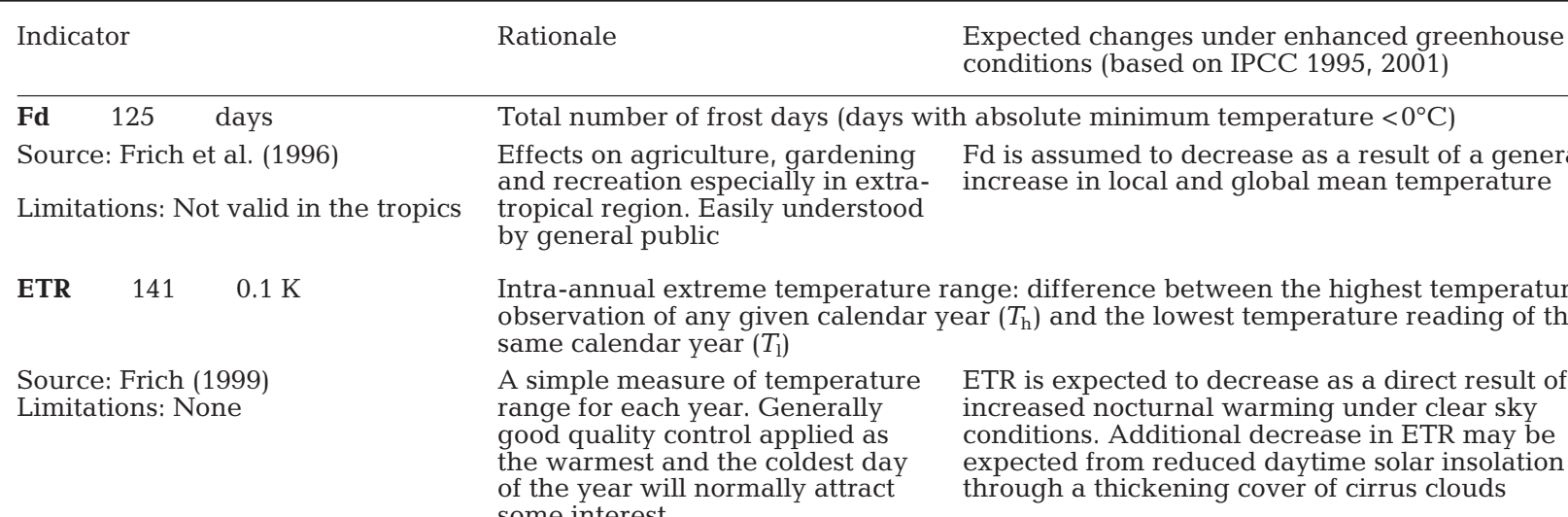

GSL 143 days

Source: Frich (1999)

Limitations:

Not valid outside mid-latitudes

HWDI 144 days

Source: This study

Limitations: Not really valid

outside mid-latitude climates

Tn90 $194 \quad \%$

Source: This study

Limitations: None

R10 606 days

Source: Frich et al. (1996)

Limitations: very regionally

dependent but still valid in all

climates analysed

CDD 641 days

Source: Frich (1999)

Limitations: None

R5d $\quad 644 \quad 0.1 \mathrm{~mm}$

Source: This study

Limitations: None

SDII $\quad 646 \quad 0.1 \mathrm{~mm} \mathrm{~d}^{-1}$

Source: This study

Limitations: None

R95T $695 \%$

Source: This study

Limitations: May be highly corre-

lated with number of extreme events some interest

through a thickening cover of cirrus clouds

Growing season length: period when $T_{\text {day }}>5^{\circ} \mathrm{C}$ for $>5 \mathrm{~d}$ and $T_{\text {day }}<5^{\circ} \mathrm{C}$ for $>5 \mathrm{~d}$ Important for agriculture

GSL is expected to increase as a direct result of increasing temperatures and indirectly as a result of reductions in snow cover

Heat wave duration index: maximum period $>5$ consecutive days with $T_{\max }>5^{\circ} \mathrm{C}$ above the 1961-1990 daily $T_{\max }$ normal

Linked with mortality statistics

Heat waves are expected to get longer and more severe due to a direct greenhouse effect under clear sky conditions and to an indirect effect of reduced soil moisture in some regions

Percent of time $T_{\min }>90$ th percentile of daily $T_{\min }$

A direct measure of the number of warm nights. This indicator could reflect potential harmful effects of the absence of nocturnal cooling, a main contributor to heat related stress

Night-time warming is expected in a greenhouse gas forced climate. This will partly come about as a clear sky radiative effect, partly be a result of increased cloud cover from additional humidity being available for nocturnal condensation

No. of days with precipitation $\geq 10 \mathrm{~mm} \mathrm{~d}^{-1}$

A direct measure of the number Greenhouse gas forcing would lead to a perturbed of very wet days. This indicator climate with an enhanced hydrological cycle. is highly correlated with total More water vapour available for condensation annual and seasonal precipitation should give rise to a clear increase in the number in most climates

Maximum no. of consecutive dry days $\left(R_{\text {day }}<1 \mathrm{~mm}\right)$

Effects on vegetation and ecosystems. Potential drought indicator. A decrease would reflect a wetter climate if change were due to more frequent wet days

Under sustained greenhouse gas forcing, the interior of continents may experience a general drying due to increased evaporation. This statement assumes that there will be a land-surface (soil moisture) feedback on precipitation. Although models in general show this, it has been quite difficult to actually detect an unambiguous signal in the observational record of soil moisture feedback on precipitation

Maximum 5 d precipitation total A measure of short-term precipitation intensity. Potential flood indicator
Greenhouse gas forcing would lead to a perturbed climate with an enhanced hydrological cycle. More water vapour available for condensation should give rise to a clear increase in the total maximum amount of precipitation for any given time period

Simple daily intensity index: annual total/number of $R_{\text {day }} \geq 1 \mathrm{~mm} \mathrm{~d}^{-1}$ A simple measure of precipitation Greenhouse gas forcing in most climate models intensity leads to higher rainfall intensities

Fraction of annual total precipitation due to events exceeding the 1961-1990 95th percentile A measure of very extreme precipitation events Greenhouse gas forcing in most climate models leads to higher rainfall intensities, particularly giving rise to a shift in the distribution 
Appendix 2. Method for finding percentage of global land area sampled showing significant change

\section{A2.1. Creating a thinned, quasi-homogeneous network of} stations

Let ID equal the interstation distance between all possible combinations of stations and let $S$ be the total number of stations received for each extreme indicator. We then sort ID into ascending order, i.e. $I D_{1}, I D_{2}, \ldots, I D_{n}$ where

$$
n=\left(\frac{S^{2}-S}{2}\right)
$$

Consider $I D_{1}$, which is the shortest interstation distance between Stns $A$ and $B$ say. We then remove one of these from the station record. The station that is removed is the station which appears first in the remaining list of $I D$ s, e.g. if $I D_{2}$ contains Stns $B$ and $C$, then Stn $B$ would be removed from the station list and hence all IDs which contain $\operatorname{Stn} B$ are removed. This process is repeated for $I D_{2}, I D_{3}, \ldots$ until a threshold value $I D_{r}$ is reached. This is determined using the criteria that we should have at least 1 station every $250000 \mathrm{~km}^{2}$. Hence

$$
\begin{aligned}
& \pi\left(I D_{r}\right)^{2}=2.5 \times 10^{5} \\
& \Rightarrow I D_{r}=282 \mathrm{~km}
\end{aligned}
$$

The stations which appear in the IDs above this threshold are kept. This ensures that more remote stations remain but thins the network where there are higher density clusters.

The following cases use the thinned network for calculation.

\section{A2.2. Testing the difference between 2 multi-decadal aver- ages (global maps)}

Let $\mathbf{X}_{\mathrm{s}}$ represent the extreme values for 1 station such that $\mathbf{X}_{\mathrm{s}}$ can be divided up into 2 periods $\mathbf{A}_{\mathrm{s}}$ and $\mathbf{B}_{\mathrm{s}}$ which both have at least 20 yr worth of data.

If we write

$$
\mathbf{X}_{\mathrm{s}}=x_{i}, X_{i+1}, \ldots, X_{\mathrm{n}}
$$

where $i \geq 1946$ and $n \leq 1999$, then we define

$$
\begin{aligned}
& \mathbf{A}_{\mathrm{s}}=x_{i}, x_{i+1}, \ldots, x_{\mathrm{m}} \\
& \mathbf{B}_{\mathrm{s}}=x_{m+1}, x_{m+2}, \ldots, x_{n}
\end{aligned}
$$

where $m=\left(\frac{n+i}{2}\right)$ and is rounded down to the nearest integer.

To test if there is any significant difference in the means between the 2 periods, a $t$-test is implemented as follows:

Calculate the sums of the squared differences from the mean for each of $\mathbf{A}_{\mathrm{s}}$ and $\mathbf{B}_{\mathrm{s}}$ such that:

$$
S \bar{x}_{\mathrm{A}}=\sum_{k=m+1}^{m}\left[x_{k}-\bar{x}_{\mathrm{A}}\right]^{2}
$$

and

$$
S \bar{x}_{\mathrm{B}}=\sum_{k=m+1}^{n}\left[x_{k}-\bar{x}_{\mathrm{B}}\right]^{2}
$$

where $\bar{x}_{\mathrm{A}}$ and $\overline{\mathrm{x}}_{\mathrm{B}}$ are the means of $\mathbf{A}_{\mathrm{s}}$ and $\mathbf{B}_{\mathrm{s}}$ respectively.

Define the null hypothesis as

$$
H_{0}: \bar{x}_{\mathrm{A}}=\bar{x}_{\mathrm{B}}
$$

If $n_{\mathrm{A}}$ and $n_{\mathrm{B}}$ are the number of elements in $\mathbf{A}_{\mathrm{s}}$ and $\mathbf{B}_{\mathrm{s}}$ respectively, then the number of degrees of freedom, $v$, is given by

$$
v=\left(n_{\mathrm{A}}+n_{\mathrm{B}}\right)-2
$$

and hence the common population variance is

$$
\alpha=\frac{S \bar{x}_{\mathrm{A}}+S \bar{x}_{\mathrm{B}}}{\nu}
$$

From Eqs (A5) \& (A6), we now have enough information to calculate a 2-tailed significance test at the $5 \%$ level of significance. The $t$-test statistic is given by

$$
t=\left|\frac{\bar{x}_{\mathrm{A}}-\bar{x}_{\mathrm{B}}}{\left(\frac{\alpha}{n_{A}}+\frac{\alpha}{n_{B}}\right)^{\frac{1}{2}}}\right|
$$

Eq. (7) now enables us to calculate the significance, $\sigma_{\mathrm{s}}$, that the means of $\mathbf{A}_{\mathrm{s}}$ and $\mathbf{B}_{\mathrm{s}}$ are significantly different at a $95 \%$ level of confidence. Hence $H_{0}$ is rejected if $\sigma_{\mathrm{S}}<0.05(5 \%)$.

Calculating the percentage difference between the means of the 2 periods, i.e.

$$
P_{\mathrm{s}}=\left(\frac{\bar{x}_{\mathrm{B}}-\bar{x}_{\mathrm{A}}}{\bar{x}_{\mathrm{B}}}\right) \times 100.0
$$

and given the latitudes and longitudes of each station, we can plot this change and show its significance, as in Figs 1a-10a.

\section{A2.3. Creating a time series of anomalies (time series plots)}

The time series of anomalies shown in Figs $1 b-10 b$ were calculated as follows. Using the definition of $x_{i}$ in Eq. (A1) we define the climatological average, $S_{j}$ for Stn $j$ using the 1961-1990 base period, i.e.

$$
S_{j}=\frac{\sum_{i=1961}^{1990} \boldsymbol{x}_{i}}{30}
$$

Calculate the percentage anomaly for each station $A_{j y}$ for each available year in the time series such that:

$$
A_{j Y}=\left(\frac{x_{Y}-S_{j}}{S}\right) \times 100.0
$$

where $1951 \leq y<1996$. Thus we can express the overall percentage anomaly $P_{Y}$ for each year as follows:

$$
P_{y}=\frac{\sum_{j=1}^{n_{y}} A_{j y}}{n_{y}}
$$

where $n_{y}$ is the number of available stations in a given year.

The values of $P_{y}$ were assigned weights proportional to the number of stations contributing data for that year. The weights were used in a weighted linear regression analysis of $P_{y}$ which calculated both the weighted least squares trend in $P_{Y}$ and its statistical significance.

The results are shown in Figs $1 \mathrm{~b}-10 \mathrm{~b}$ with inserts showing the value of the weighting function. 
Peterson TC, Vose RS (1997) An overview of the Global Historical Climatology Network temperature database. Bull Am Meteorol Soc 78:2837-2849

Peterson T, Daan H, Jones P (1997) Initial Selection of a GCOS Surface Network. Bull Am Meteorol Soc 78:2145-2152

Peterson T, Easterling DR, Karl TR, Groisman P and 17 others (1998) Homogeneity adjustments of in situ atmospheric climate data: a review. Int J Climatol 18:1493-1517

Plummer N, Lin Z, Torok S (1995) Trends in the diurnal temperature range over Australia since 1951. Atmos Res 37: 79-86

Ramsey FL, Schafer DW (1997) The statistical sleuth: a course in methods of data analysis. Wadsworth Publishing $\mathrm{Co}_{\text {, }}$ Belmont, CA, p 53-80

Torok SJ, Nicholls N (1996) A historical annual temperature

Editorial responsibility: Clare Goodess,

Norwich, United Kingdom dataset for Australia. Aust Meteorol Mag 45:251-260

Travis DJ, Changnon SA (1997) Evidence of jet contrail influences on regional-scale diurnal temperature range. J Weather Modif 29:74-83

Trewin BC (1999) The development of a high-quality daily temperature data set for Australia, and implications for the observed frequency of extreme temperatures. In: Meteorology and oceanography at the millenium: AMOS '99. Proceedings of the Sixth National Australian Meteorological and Oceanographic Society Congress, Canberra, 1999, p 87

Tuomenvirta H, Alexandersson H, Drebs A, Frich P, Nordli PO (2000) Trends in Nordic and Arctic temperature extremes and ranges. J Clim 13:977-990

Zhang X, Hogg WD, Mekis E (2001) Spatial and temporal characteristics of heavy precipitation events over Canada. $\mathrm{J}$ Clim (in press)

Submitted: December 7, 2000; Accepted: April 30, 2001 Proofs received from author(s): September 27, 2001 